\title{
Polyglycidol-Stabilized Nanoparticles as a Promising Alternative to Nanoparticle PEGylation: Polymer Synthesis and Protein Fouling Considerations
}

Haiqin Du, ${ }^{a}$ Fernando A. de Oliveira, ${ }^{b}$ Lindomar J. C. Albuquerque, ${ }^{b}$ Guillaume Tresset, ${ }^{c}$ Ewa Pavlova, ${ }^{d}$ Cécile Huin, ${ }^{e}$ Philippe Guégan ${ }^{a}$ and Fernando C. Giacomelli $a, b, *$

${ }^{a}$ Equipe Chimie des Polymères, Institut Parisien de Chimie Moléculaire (UMR-CNRS 8232), Sorbonne Université, Paris, France.

${ }^{b}$ Centro de Ciências Naturais e Humanas, Universidade Federal do ABC, Santo André, Brazil.

${ }^{c}$ Laboratoire de Physique des Solides, CNRS, Univ. Paris Sud, Université Paris Saclay, Orsay Cedex, France.

${ }^{d}$ Institute of Macromolecular Chemistry, Prague, Czech Republic.

${ }^{e}$ LAMBE, Université Evry, CNRS, CEA, Université Paris-Saclay, Evry, France.

*Corresponding Author: $\quad$ Fernando Carlos Giacomelli 
e-mail: fernando.giacomelli@ufabc.edu.br

\begin{abstract}
We herein demonstrate the outstanding protein-repelling characteristic of starlike micelles and polymersomes manufactured from amphiphilic block copolymers made by poly(butylene oxide) (PBO) hydrophobic segments and polyglycidol (PGL) hydrophilic outer shells. Although positively charged proteins (herein modeled by lysozyme) may adsorb onto the surface of micelles and polymersomes where the assemblies are stabilized by short PGL chains (degree of polymerization smaller then 15), the protein adsorption vanishes when the degree of polymerization of the hydrophilic segment (PGL) is higher than 20, regardless the morphology. This has been probed by using three different model proteins which are remarkable different concerning molecular weight, size and zeta potential (bovine serum albumin - BSA, lysozyme and immunoglobulin G - IgG). Indeed, the adsorption of the most abundant plasma protein (herein modeled as BSA) is circumvented even by using very short PGL shells due to the highly negative zeta potential of the produced assemblies which presumably promotes protein-nanoparticle electrostatic repulsion. The highly negative zeta potential, on the other hand, enables lysozyme adsorption and the phenomenon is governed by electrostatic forces as evidenced by isothermal titration calorimetry. Nevertheless, the protein coating can be circumvented by slightly increasing the degree of polymerization of the hydrophilic segment. Notably, the PGL length required to circumvent protein fouling is significantly smaller than the one required for PEO. This feature and the safety concerns regarding the synthetic procedures on the preparation of poly(ethylene oxide)-based amphiphilic copolymers might make polyglycidol a promising alternative towards the production of non-fouling particles.
\end{abstract}




\section{INTRODUCTION}

Recently, great concerns have been invoiced regarding the safe use of nanotechnology-based platforms for healthcare thereby calling for a deeper understanding of the processes occurring at the interface between nanomaterials and biological systems. The nanoparticle-based therapeutic agents are prone to interaction with biomolecules whenever circulating in the bloodstream. The proteins adsorption onto the surface of nanoparticles and the self-development of protein coronas has been evidenced to introduce several shortcomings towards the application of nanoparticles in medicine. The presence of protein coronas usually results in the inability of the cells to encounter naked particles ${ }^{1-3}$ impacting on their targeting ability, toxicity, cellular uptake, circulation lifetime, signaling, therapeutic effects, intracellular transport and biodistribution. ${ }^{4,5}$ The emergence of protein coronas onto the surface of colloidal materials is influenced by their structural features (morphology, size, shape, chemical nature, surface charge $)^{6}$ and by the protein-particle chemical compatibility. ${ }^{7}$ The protein adsorption is usually governed by intermolecular forces including van der Waals interactions, hydrogen bonding, electrostatic and hydrophobic effects. ${ }^{8,9}$ The strength of the interactions determines the formation, chemical nature, binding affinity and binding ratio of adsorbed biomacromolecules.

Although the emergence of protein coronas may bring benefits to dispersed nanomaterials (particularly with regard to cytotoxicity), ${ }^{10,11}$ for most of the applications they are considered artifacts that have to be at least substantially reduced. ${ }^{9,12-14}$ Typically, the presence of highly hydrophilic polymer chains at the interfaces remarkably reduces interparticle attractive forces thereby reducing protein adsorption. The hydrophilic polymer poly(ethylene glycol) - PEG - is typically used for such 
purpose. Nevertheless, it has been highlighted relevant shortcomings in this regard: i) PEG can trigger the activation of the complement system ${ }^{15}$, iii) its antibodies (anti-PEG) are known to be produced by the immune system thereby reducing the therapeutic efficacy of PEG-based nanomedicines ${ }^{16,17}$, iv) PEGylation cannot completely prevent protein adsorption. ${ }^{18}$ Accordingly, there is a growing body of novel polymers being investigated as suitable replacements to PEGylation.

In this framework, linear polyglycidol (PGL) is herein investigated as one of the alternatives. The main chain of polyglycidol is similar to PEG, except that each repeating unit of polyglycidol contains an additional hydroxymethyl group. Looking at the synthetic point of view, well-defined PGL are often prepared via anionic ring opening polymerization (AROP) of glycidyl ethers combined with a deprotection step. ${ }^{19}$ The common used glycidyl ethers are tert-butylglycidyl ether (tBuGE) and ethoxyethyl glycidyl ether (EEGE) due to the facility of deprotection. ${ }^{20-22}$ Besides, there have been recently a lot of efforts towards finding efficient organo-catalysts for controlled polymerization of glycidyl ethers and other 1,2-subsituted epoxides by AROP. Amongst than, the tBuP4 is so far the preferred organic super base with low nucleophilicity. The tBuP4-catalysed AROP was evidenced to provide controlled and metal-free production of narrowly-distributed polyepoxides under mild conditions. ${ }^{23}$ The polymerization of various epoxide monomers including 1,2-alkene epoxides such as butylene oxide (BO), propylene oxide (PO) ${ }^{21,24}$ and glycidyl ethers such as allyl glycidyl ether (AGE) ${ }^{25}$ and EEGE $^{21,25}$ has been successfully achieved by using the such synthetic strategy. Additionally, tBuP4-catalyzed AROP shows living character allowing the sequential block copolymerization of two epoxide monomers such as PO/EEGE ${ }^{26}$ and decyl glycidyl ether/2-(2-(2-methoxyethoxy)ethoxy)ethyl glycidyl ether ${ }^{27,28}$ for instance. 
Taking into account the potential biomedical applications, PGL and PEO are reported to be similar regarding biocompatibility ${ }^{29}$, and PGL-grafted surfaces were reported to resist protein adsorption ${ }^{30,31}$ and biofilm growth. ${ }^{32}$ Nevertheless, the protein adsorption onto PGL-stabilized nanoparticles (spherical surfaces) was never explored to the best of our knowledge. Therefore, we consider of due relevance the investigations regarding protein adsorption onto PGL-stabilized nanoparticles since such polymers can be thought as a promising solution to overcome the limitations of other polymers (including PEG).

Accordingly, these investigations were focused on amphiphilic copolymers having a polyglycidol (PGL) hydrophilic shell linked to poly(butylene oxide) (PBO) hydrophobic segments, either diblock, or triblock copolymers. We herein explored the syntheses and characterizations of such novel amphiphilic copolymers, and their selfassembly in aqueous solution. Subsequently, the protein-repelling character of the different morphologies produced was probed by using model proteins highly dissimilar with regard to size, molecular weight and isoelectric point.

\section{MATERIALS AND METHODS}

\section{Syntheses and Characterization of the Diblock and Triblock Copolymers}

\section{Materials}

The monomers butylene oxide (BO, 99\%, Aldrich), ethoxyethyl glycidyl ether (EEGE, prepared from glycidol (96\%, Aldrich) and ethyl vinyl ether (99\%, Aldrich) were dried twice over calcium hydride $\left(\mathrm{CaH}_{2}\right.$, ca. 93\%, ACROS) via vacuum distillation and further stored in glovebox before use. Benzyl alcohol (BA, anhydrous, 99.8\%, SigmaAldrich) and tBuP4 ( 0.8 mol. $\mathrm{L}^{-1}$ in n-hexane, Sigma-Aldrich) were also stored in glovebox before use. $\mathrm{CaH}_{2}$, neutral alumina (Sigma-Aldrich), 1,4-benzene dimethanol 
(BDM, 99\%, Aldrich), dichloromethane (DCM, VWR Chemical) and methanol (MeOH, VWR chemical) were used as received. Anhydrous toluene and THF for polymerizations were purified using an MBRAUN solvent purification system (MB SPS COMPACT) consisting of an activated alumina column and an activated copper catalyst column. Polymerizations were carried out in an MBRAUN stainless steel glovebox equipped with a gas purification system (molecular sieves and copper catalyst) and dry argon atmosphere $\left(\mathrm{H}_{2} \mathrm{O}<0.5 \mathrm{ppm}\right)$. The moisture content in the glovebox was monitored by an MB-MO-SE 1 moisture probe.

\section{Syntheses of Diblock copolymers $\left(P G L_{n}-b-P B O_{m}\right)$}

The diblock copolymers $\left(\mathrm{PGL}_{\mathrm{n}}-b-\mathrm{PBO}_{\mathrm{m}}\right.$ ) were prepared via tBuP4-catalyzed sequential AROP followed with an acidic deprotection. The typical procedure is described for $\mathrm{PGL}_{50}-b-\mathrm{PBO}_{13}$ : tBuP4 (0.8 mol.L ${ }^{-1}$ in $\mathrm{n}$-hexane, $125 \mu \mathrm{L}, 0.1 \mathrm{mmol}, 0.5$ equiv.) was added into a solution of BA (20.7 $\mu \mathrm{L}, 0.2 \mathrm{mmol}, 1$ equiv.) and BO (0.1872 g, $2.6 \mathrm{mmol}$, 13 equiv.) in toluene $(0.5 \mathrm{~mL})$ to trigger the homopolymerization of $\mathrm{BO}$. After stirring at $25{ }^{\circ} \mathrm{C}$ for $24 \mathrm{~h}$, an aliquot of the reaction mixture was withdrawn and applied to ${ }^{1} \mathrm{H}$ NMR characterization to check the conversion of BO. After confirming the consumption of BO, the second monomer, EEGE (1.4016 g, 9.6 mmol, 47 equiv.) was added to start the copolymerization, and the reaction was carried out for $24 \mathrm{~h}$ at $25{ }^{\circ} \mathrm{C}$ and further quenched by DI water. The reaction mixture was then concentrated giving a brown viscous liquid. The crude product was diluted with DCM and eluted through a short neutral alumina column to remove tBuP4. The eluent was concentrated giving the diblock copolymer PEEGE $47-b-\mathrm{PBO}_{13}$ as a colourless viscous liquid. Then, the hydroxyls were deprotected in acidic conditions: PEEGE $47-b-\mathrm{PBO}_{13}\left(\mathrm{Mn}_{\text {theo }} 4.5 \mathrm{~kg} / \mathrm{mol}\right.$, $0.45 \mathrm{~g}, 0.1 \mathrm{mmol})$ was dissolved in $\mathrm{MeOH}(7.1 \mathrm{~mL})$ and an amount of $\mathrm{HCl}$ solution (2 
mol. $\mathrm{L}^{-1}$ in $\mathrm{MeOH}, 2.4 \mathrm{~mL}$, $4.8 \mathrm{mmol}$ ) was added into the polymer solution. The mixture was stirred at room temperature for $4 \mathrm{~h}$ before being neutralized by $\mathrm{NaHCO}_{3}$. The solid was removed by filtration and the filtrate was concentrated to give the deprotected diblock copolymer $\left(\mathrm{PGL}_{50}-b-\mathrm{PBO}_{13}\right)$ as a white waxy solid. The $\mathrm{PGL}_{\mathrm{n}}-b-\mathrm{PBO}_{\mathrm{m}}$ block copolymers with different values of $\mathrm{m}$ and $\mathrm{n}$ were prepared following the same procedure but varying the BO/EEGE/BA feeding ratio.

Syntheses of Triblock Copolymers ( $\left.P G L_{n}-b-P B O_{2 m}-b-P G L_{n}\right)$

Similar synthetic procedure was applied to prepare the triblock copolymers. The typical procedure is described for $\mathrm{PGL}_{10}-b-\mathrm{PBO}_{88}-b-\mathrm{PGL}_{10}$ : tBuP4 (0.8 mol.L ${ }^{-1}$ in n-hexane, 125 $\mu \mathrm{L}, 0.1 \mathrm{mmol}, 0.5$ equiv.) was added into the solution of BDM (27.6 mg, $0.2 \mathrm{mmol}, 1$ equiv.) and BO (1.1520 g, $16.0 \mathrm{mmol}, 80$ equiv.) in THF (1.3 mL). After stirring at 50 ${ }^{\circ} \mathrm{C}$ for $24 \mathrm{~h}$, the completion of the homopolymerization was confirmed by ${ }^{1} \mathrm{H}$ NMR. Then, EEGE (0.6716 g, $4.6 \mathrm{mmol}, 23$ equiv.) was added to start the copolymerization, and the reaction was carried out for $24 \mathrm{~h}$ at $25^{\circ} \mathrm{C}$ and further quenched by DI water. The reaction mixture was then concentrated giving a brown viscous liquid. The crude product was diluted with DCM and eluted through a short neutral alumina column to remove tBuP4. The eluent was concentrated to give the triblock copolymer PEEGE ${ }_{10}-b$ $\mathrm{PBO}_{88}-b-\mathrm{PEEGE}_{10}$ as a colourless transparent viscous liquid. To reveal the hydroxyl groups, an amount of $\mathrm{HCl}$ solution (2 mol/L in $\mathrm{MeOH}, 1.2 \mathrm{~mL}, 2.4 \mathrm{mmol}$ ) was added into the solution of PEEGE ${ }_{10}-b-\mathrm{PBO}_{88}-b-\mathrm{PEEGE}_{10}\left(\mathrm{Mn}_{\text {theo }} 7.6 \mathrm{~kg} / \mathrm{mol}, 0.76 \mathrm{~g}, 0.1 \mathrm{mmol}\right)$ in $\mathrm{MeOH}$ (3.5 mL). After stirring at room temperature for $4 \mathrm{~h}$, the mixture was neutralized by $\mathrm{NaHCO}_{3}$. The solid was removed and the filtrate was concentrated giving the deprotected triblock copolymer $\left(\mathrm{PGL}_{10}-b-\mathrm{PBO}_{88}-b-\mathrm{PGL}_{10}\right)$ as a white waxy solid. The other triblock copolymers ( $\mathrm{PGL}_{\mathrm{n}}-b-\mathrm{PBO}_{2 \mathrm{~m}}-b-\mathrm{PGL}_{\mathrm{n}}$ ) with different values of $\mathrm{m}$ and 
n were synthesized by varying the BO/EEGE/BDM feeding ratio and following the same procedures.

\section{Characterization of the Block Copolymers}

The ${ }^{1} \mathrm{H}$ NMR (300 MHz) spectra were recorded on a Bruker Ultra Shield 300 NMR spectrometer. All ${ }^{1} \mathrm{H}$ NMR spectra were analyzed with MestReNova 9.1.0 software and internally referenced to residual proton signals of the deuterated solvents, including $\mathrm{CDCl}_{3}-\mathrm{d}_{1}$, THF- $\mathrm{d}_{6}$ and MeOD- $\mathrm{d}_{4}$. Size exclusion chromatography were performed at $60{ }^{\circ} \mathrm{C}$ in DMF (containing 1.0 g. $\mathrm{L}^{-1}$ lithium bromide as an additive at a flow rate of $0.8 \mathrm{~mL} \cdot \mathrm{min}^{-1}$ ) using a Viscotek gel permeation chromatography system (TDA 305) equipped with one PSS-GRAM $30 \AA$ column $(8 \mathrm{~mm} \times 300 \mathrm{~mm})$ and two PSS GRAM $1000 \AA$ columns $(8 \mathrm{~mm} \times 300 \mathrm{~mm})$. All polymers were injected at a concentration of $5 \mathrm{mg} \cdot \mathrm{mL}^{-1}$ after filtration through $0.2 \mu \mathrm{m}$ syringe filter. OminiSEC 5.12 software was used to acquire and analyze the data. Number-average molecular weight $\left(\mathrm{M}_{\mathrm{n}}(\mathrm{SEC})\right)$ and polymer dispersity index $(\bigoplus)$ were determined on the basis of poly(methyl methacrylate) (PMMA) standards (from Polymer Standard Services) using RI detector.

\section{Manufacturing of the Polymer Colloids}

The manufacturing of the polymersomes and block copolymer micelles was conducted by thin-film hydration. The $\mathrm{PGL}_{n}-b-\mathrm{PBO}_{2 m}-b-\mathrm{PGL}_{n}$ and $\mathrm{PGL}_{n}-b-\mathrm{PBO}_{m}$ block copolymers (5.0 mg) were dissolved in glass vials using a good organic solvent for both blocks (ethanol or methanol depending on the PBO:PGL weight ratio). The organic solvent was left to evaporate for $72 \mathrm{~h}$ resulting in polymer films sited at the bottom of glass vials. The polymer films were subsequently hydrated by the addition of $5.0 \mathrm{~mL}$ of 
distilled water thereby resulting in self-assembled structures. The solutions were subsequently centrifuged and-or filtered to remove dust and/or ill-aggregates.

\section{Behavior of the Polymeric Assemblies in Protein Environments}

The behavior of the polymeric assemblies in protein environments was evaluated firstly by monitoring changes in the size of the assemblies as a function of protein concentration by dynamic light scattering. The thermodynamic parameters related to the protein adsorption phenomena were determined through isothermal titration calorimetry (ITC). Furthermore, fluorescence and circular dichroism spectroscopy data were acquired in order to identify the protein quenching mechanism and conformational changes. All the details regarding the employed methods of characterization are detailed below.

\section{Methods of Characterization}

Dynamic Light Scattering: The dynamic light scattering (DLS) measurements were acquired using a ZetaSizer Nano ZS90. The averaged intensity autocorrelation functions were evaluated using non-negative least squares (NNLS) analysis implemented in the Zetasizer software therefore resulting in distribution of sizes. The hydrodynamic radius $\left(R_{H}\right)$ of the nanoparticles was determined using the well-known Stokes-Einstein relation with $D=\tau^{-1} q^{-2}$ :

$$
R_{H}=\frac{k_{B} T q^{2}}{6 \pi \eta} \tau
$$

where $k_{B}$ is the Boltzmann constant, $T$ is the absolute temperature, $q$ is the scattering vector, $\eta$ is the viscosity of the solvent and $\tau$ is the mean relaxation time related to the $\ln g_{1}(t)=\ln C-\Gamma t+\frac{\mu_{2}}{2} t^{2} \ldots$ 
diffusion of the nanoparticles. The autocorrelation functions were also analyzed using the Cumulant method..$^{33}$

where $C$ is the amplitude, $\Gamma$ is the relaxation frequency $\left(\tau^{-1}\right)$ and the parameter $\mu_{2}$ is known as the second-order cumulant. The polydispersity index of the samples (PDI) was then computed as PDI $=\mu_{2} / \Gamma^{2}$.

Static Light Scattering: The SLS data were acquired to determine the molecular weight $\left(M_{w(N P s)}\right)$ and number of aggregation $\left(N_{a g g}\right)$ of the assemblies. The light scattering intensity was monitored at scattering angle $\theta=90^{\circ}$ as a function of polymer concentration and the values of $M_{w(N P s)}$ were estimated by using the Debye plot:

$$
\frac{K c}{R_{\theta}}=\frac{1}{M_{w(N P s)}}+2 A_{2} c
$$

the concentration $c$ is given in $\mathrm{mg} \cdot \mathrm{mL}^{-1}$ and $K$ is the optical constant expressed by:

$$
K=\frac{4 \pi^{2} n^{2}\left(\frac{d n}{d c}\right)^{2}}{N_{A} \lambda^{4}}
$$

$R_{\theta}$ (Rayleigh ratio) is the normalized scattered intensity (toluene was used as standard solvent), $n$ is the refractive index of the solvent, $N_{\mathrm{A}}$ is the Avogadro's number and $\mathrm{d} n / \mathrm{d} c$ is the refractive index increment determined based on the refractive index increments of PGL and PBO blocks as well as their weight fraction (w) using Equation 5.

$$
\frac{d n}{d c}=\left(n_{P B O} \cdot w_{P B O}+n_{P G L} \cdot w_{P G L}\right)-n_{\text {water }}
$$


The refractive index of PBO ( $\left.n_{\mathrm{PBO}}\right)$ and PGL ( $\left.n_{\mathrm{PGL}}\right)$ are respectively 1.454 and 1.474 and the weight fractions are given in Table 1.

Taking into account the Equation 3, by plotting $K c / R_{\theta} v s . c$ at a given angle, the molecular weight is extracted from the reinverse of the intercept. The number of aggregation is determined as:

$$
N_{\text {agg }}=\frac{M_{w(N P s)}}{M_{w(\text { unimer })}}
$$

Electrophoretic Light Scattering: The ELS measurements (acquired using a Zetasizer Nano-ZS instrument) were used to determine the average zeta potential (६) of the nanoparticles. The values of electrophoretic mobility $\left(U_{\mathrm{E}}\right)$ were converted to values of $\zeta$-potential (mV) through the Henry's equation:

$$
U_{E}=\frac{2 \varepsilon \zeta f(k a)}{3 \eta}
$$

where $\varepsilon$ is the dielectric constant of the medium and $\eta$ is the viscosity. Furthermore, $f(k a)$ is the Henry's function, which was calculated through the Smoluchowski approximation $f(k a)=1.5$.

Transmission Electron Microscopy (TEM): The morphology of self-assembled nanoparticles was also probed by transmission electron microscopy (TEM) using a Tecnai G2 Spirit Twin 120kV (FEI, Czech Republic) microscope. Two- $\mu \mathrm{L}$ of the aqueous solutions were dropped onto a copper TEM microscopic grid (400 mesh) coated with thin, electron-transparent carbon film. The excess of solution was removed by touching the bottom of the grid with filtering paper. This fast removal of the solution was performed after 5 min of sedimentation in order to minimize oversaturation during 
the drying process. The assemblies were negatively stained with uranyl acetate $(2 \mu \mathrm{L}$ of 2 wt.\% solution dropped onto not completely dried nanoparticles and removed after 30 $\mathrm{s}$ in the same way as described above). The samples were left to dry completely at environment temperature and then observed by TEM. Under these conditions, the micrographs displayed negatively stained background with bright nanoparticles.

\section{Small-Angle X-ray Scattering (SAXS):}

Isothermal Titration Calorimetry (ITC): The thermodynamic parameters of protein-nanoparticle interaction were determined by isothermal titration calorimetry (ITC) performed at $25{ }^{\circ} \mathrm{C}$ using a MicroCal iTC200 calorimeter. The reference cell was filled with water, the sample cell was filled with $2.0 \mathrm{mg} \cdot \mathrm{mL}^{-1}$ of block copolymer solution and the syringe was filled with $1.6 \mathrm{mg} \cdot \mathrm{mL}^{-1}$ of protein solutions. The titrations were performed by injecting the protein solutions in the sample cell every predetermined interval of time. The ITC raw data were integrated from a baseline to give the heat per injection as a function of the protein-to-nanoparticle weight ratio. The heat of dilution of protein solution was negligible, as determined in a blank experiment where protein solutions were injected into the sample cell containing only PBS buffer.

Fluorescence Spectroscopy: The fluorescence spectra were recorded on a Varian Cary Eclipse fluorescence spectrophotometer, in the range 300-450 nm after progressive additions of nanoparticles into the protein solutions, with excitation wavelength of 280 nm and using a quartz cell with $10.0 \mathrm{~mm}$ optical path at $296 \mathrm{~K}$. 
Circular Dichroism Spectroscopy (CD): The CD data were acquired using a Jasco J-815 circular dichroism spectrometer and quartz cuvette with $1.0 \mathrm{~mm}$ optical path. The spectra was collected in the range $200-260 \mathrm{~nm}$ at room temperature and corrected by subtracting the solvent background.

\section{RESULTS AND DISCUSSIONS}

\section{Syntheses and Characterization of the Block Copolymers}

Taking into account the molar mass of the repeating units (74.0 and 72.0 g.mol ${ }^{-1}$ respectively for PGL and PBO) it has been designed the syntheses of block copolymers with distinct hydrophilic-to-hydrophobic weight ratios towards the manufacturing of different morphologies. The chemical structure of the amphiphilic block copolymers are given in Scheme 1 along to the synthetic procedures used in their manufacturing.
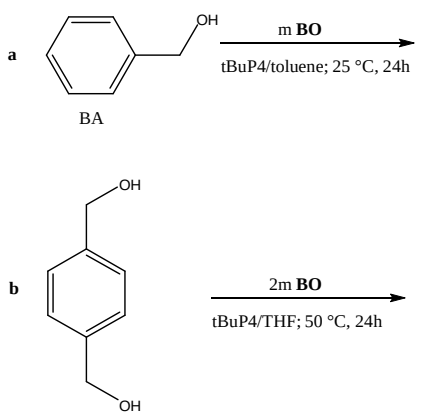

BDM

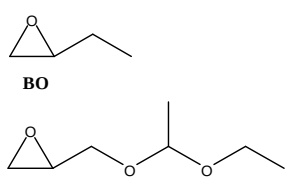

EEGE
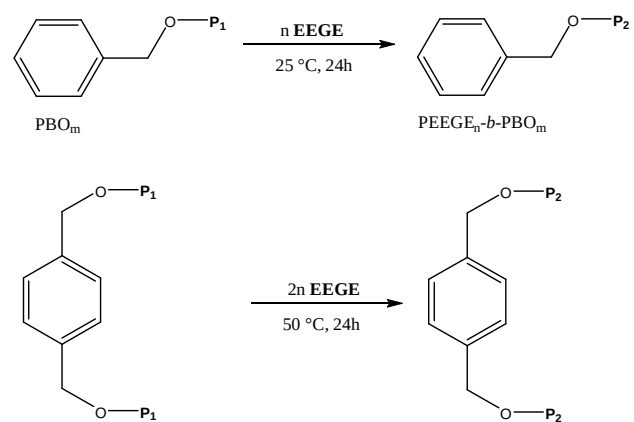

$\mathrm{PBO}_{2 \mathrm{~m}}$
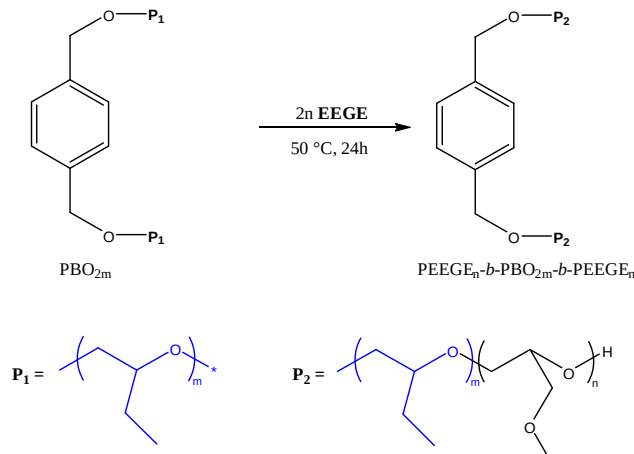
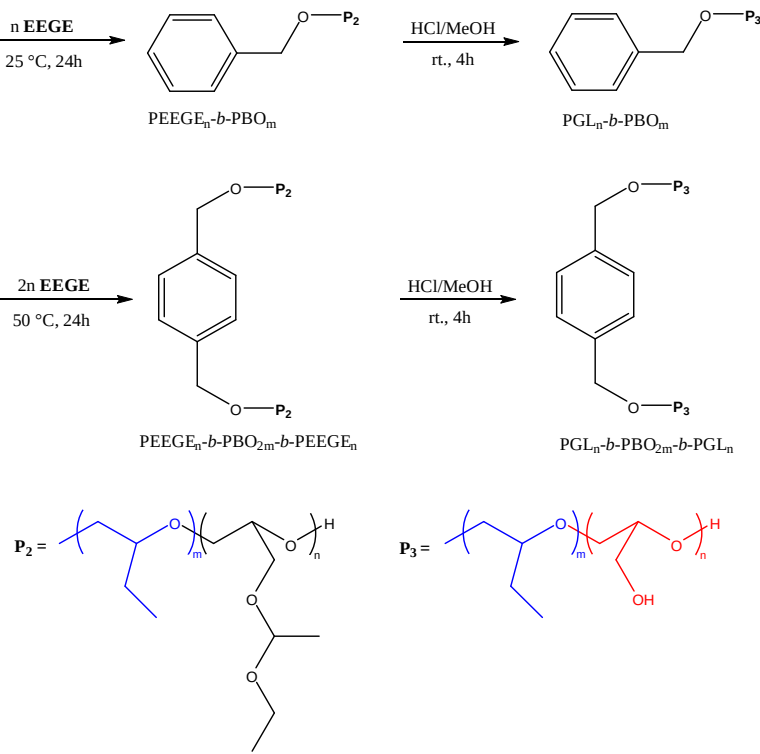

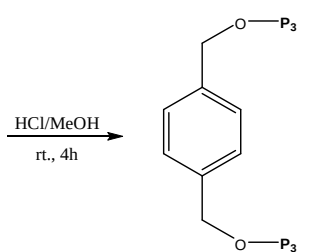

$\mathrm{PGL}_{\mathrm{n}}-b-\mathrm{PBO}_{2 \mathrm{~m}}-b-\mathrm{PGL}$

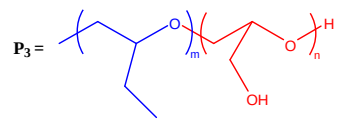

Scheme 1. Synthetic procedures of the amphiphilic block copolymers $\mathrm{PGL}_{\mathrm{n}}-b-\mathrm{PBO}_{\mathrm{m}}$ (a) and $\mathrm{PGL}_{\mathrm{n}}-b-\mathrm{PBO}_{2 \mathrm{~m}}-b-\mathrm{PGL}_{\mathrm{n}}$ (b). The hydrophobic PBO segment is given in blue.

The diblock $\mathrm{PGL}_{\mathrm{n}}-b-\mathrm{PBO}_{\mathrm{m}}$ and triblock $\mathrm{PGL}_{\mathrm{n}}-b-\mathrm{PBO}_{2 \mathrm{~m}}-b-\mathrm{PGL}_{\mathrm{n}}$ copolymers were synthesized via tBuP4-catalyzed sequential anionic ring opening polymerization 
(AROP) of butylene oxide (BO) and ethoxyethyl glycidyl ether (EEGE) with BA or BDM as mono- or bi-functional initiator, respectively, followed by acidic deprotection to reveal the hydroxyl functions and provide a linear polyglycidol (Scheme 1). The tBuP4-catalyzed sequential AROP was conducted at $25^{\circ} \mathrm{C}$ and $50{ }^{\circ} \mathrm{C}$ for diblock and triblock copolymerization, respectively. After the first 24h, BO had a quantitative conversion which was confirmed by ${ }^{1} \mathrm{H}$ NMR. Then, EEGE was added and the copolymerization was performed for another 24h. After quenching with $\mathrm{H}_{2} \mathrm{O}$ and removal of tBuP4, the diblock $\left(\mathrm{PEEGE}_{\mathrm{n}}-b-\mathrm{PBO}_{\mathrm{m}}\right)$ or triblock $\left(\mathrm{PEEGE}_{\mathrm{n}}-b-\mathrm{PBO}_{2 \mathrm{~m}}-b-\right.$ PEEGE $_{n}$ ) copolymers were obtained. To get the PGL blocks, the acetal groups in EEGE units were cleaved under acidic conditions. The intermediates and products in diblock copolymerization, including $\mathrm{PBO}_{\mathrm{m}}$ (homopolymerization mixture in fact), $\mathrm{PEEGE}_{\mathrm{n}}-b$ $\mathrm{PBO}_{\mathrm{m}}$ and $\mathrm{PGL}_{\mathrm{n}}-b-\mathrm{PBO}_{\mathrm{m}}$ were characterized by ${ }^{1} \mathrm{H}$ NMR (Figure $\mathrm{S} 1$, Supporting Informations) and GPC (Figure S2, Supporting Informations). In the ${ }^{1} \mathrm{H}$ NMR spectrum of $\mathrm{PBO}_{\mathrm{m}}$ (Figure $\left.\mathrm{S} 1 \mathrm{a}\right)$ the peaks corresponding to the protons of benzyl group of the initiator (4.55 ppm), the polyether backbone (3.78 - $3.23 \mathrm{ppm}$ ) and the pendant ethyl in BO unit (1.55 and $0.94 \mathrm{ppm})$ were detected. After copolymerization with EEGE, the characteristic peak belonging to methine group in EEGE unit (4.69 ppm) appeared in the ${ }^{1} \mathrm{H}$ NMR spectrum of $\mathrm{PEEGE}_{\mathrm{n}}-b-\mathrm{PBO}_{\mathrm{m}}$ (Figure S1b). By calculating the integral ratio of methyl protons in BO unit or methine protons in EEGE unit to benzyl protons in BA the values of $\mathrm{m}$ or $\mathrm{n}$ could be determined. The corresponding number-average molecular weight $\left(\mathrm{M}_{\mathrm{n}(\mathrm{NMR})}\right)$ is close to the theoretical value $\left(\mathrm{M}_{\mathrm{n}(\text { theo })}\right)$ calculated from the feeding ratio of BO/EEGE/BA (Row 2, Table 1). In addition, the GPC traces of $\mathrm{PBO}_{\mathrm{m}}$ (Figure S2a) and $\mathrm{PEEGE}_{\mathrm{n}}-b-\mathrm{PBO}_{\mathrm{m}}$ (Figure S2b) were both unimodal with low dispersity. The results altogether demonstrate that the tBuP4-catalyzed sequential AROP is well controlled. To get PGL blocks, the acetal groups in EEGE units were 
cleaved under acidic conditions. The deprotection efficiency was confirmed by ${ }^{1} \mathrm{H}$ NMR (Figure S1c), as the characteristic peak belonging to methine protons in EEGE units (4.69 ppm) disappeared. In addition, the DPs of BO and EEGE in PEEGE $-b-\mathrm{PBO}_{\mathrm{m}}$ were consistent with the DPs of $\mathrm{BO}$ and glycidol (GL) in $\mathrm{PGL}_{\mathrm{n}}-b-\mathrm{PBO}_{\mathrm{m}}$ indicating the acidic conditions used are not harmful to the polyether backbone. Additionally, the GPC trace (Figure S2c) is unimodal and narrowly distributed with a shift in elution volume to lower molar mass as a results of the deprotection. Following the same procedure, although starting with different feeding ratios, the other $\mathrm{PGL}_{\mathrm{n}}-b-\mathrm{PBO}_{\mathrm{m}}$ block copolymers could be synthesized (Row 1, Table 1). Altogether, the characterization results demonstrated the synthetic procedure leads to controlled diblock copolymer architectures.

Table 1. Characteristics of the block copolymers according to the weight fraction of PGL block ( $\left.\mathrm{W}_{\mathrm{PGL}}\right)$.

\begin{tabular}{|c|c|c|c|c|c|c|c|c|c|}
\hline \multirow[t]{2}{*}{ Entry* } & \multirow[t]{2}{*}[\mathrm{BO}]{$_{0} /[\mathrm{EEGE}]_{0} /[\mathrm{I}]_{0}{ }^{(1)}$} & \multicolumn{2}{|c|}{ Theoretical results ${ }^{(2)}$} & \multicolumn{3}{|c|}{${ }^{1} \mathrm{H}$ NMR results ${ }^{(3)}$} & \multirow[b]{2}{*}{ WPGL,NMR } & \multicolumn{2}{|c|}{ SEC results ${ }^{(4)}$} \\
\hline & & $\begin{array}{l}\mathrm{Mn}_{\text {theo. }} \\
(\mathrm{kg} / \mathrm{mol})\end{array}$ & WPGL,theo. & $\mathrm{DP}_{\mathrm{BO}}$ & $\mathrm{DP}_{\mathrm{GL}}$ & $\begin{array}{l}\mathrm{Mn}_{\mathrm{NMR}} \\
(\mathrm{kg} / \mathrm{mol})\end{array}$ & & $\begin{array}{l}\mathrm{Mn}_{\mathrm{SEC}} \\
(\mathrm{kg} / \mathrm{mol})\end{array}$ & 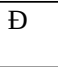 \\
\hline $\mathrm{PGL}_{15}-b-\mathrm{PBO}_{40}$ & $39 / 16 / 1$ & 4.1 & 0.28 & 40 & 15 & 4.1 & 0.27 & 5.1 & 1.06 \\
\hline $\mathrm{PGL}_{50}-b-\mathrm{PBO}_{13}$ & $13 / 47 / 1$ & 4.5 & 0.77 & 14 & 57 & 5.3 & 0.79 & 5.2 & 1.13 \\
\hline $\mathrm{PGL}_{10}-b-\mathrm{PBO}_{88}-\mathrm{PGL}_{10}$ & $80 / 24 / 1$ & 8.0 & 0.22 & 88 & 19 & 7.9 & 0.18 & 8.7 & 1.10 \\
\hline $\mathrm{PGL}_{20}-b-\mathrm{PBO}_{84}-\mathrm{PGL}_{20}$ & $84 / 41 / 1$ & 9.2 & 0.33 & 89 & 35 & 9.2 & 0.29 & 10.0 & 1.09 \\
\hline $\mathrm{PGL}_{15}-\mathrm{b}-\mathrm{PBO}_{44}-\mathrm{PGL}_{15}$ & $41 / 32 / 1$ & 5.4 & 0.43 & 44 & 30 & 5.5 & 0.40 & 7.6 & 1.08 \\
\hline $\mathrm{PGL}_{11}$-b-PBO ${ }_{22}-\mathrm{PGL}_{11}$ & $21 / 20 / 1$ & 3.0 & 0.47 & 22 & 22 & 3.4 & 0.49 & 4.9 & 1.09 \\
\hline $\mathrm{PGL}_{22}$-b-PBO ${ }_{13}-\mathrm{PGL}_{22}$ & $13 / 47 / 1$ & 4.5 & 0.77 & 14 & 57 & 5.3 & 0.79 & 5.2 & 1.13 \\
\hline
\end{tabular}

*Entries are named by theoretical formulation. The table is listed as a function of the increased amount of theoretical weight fraction of PGL block (W $\mathrm{W}_{\mathrm{PGL}, \text { theo. }}$ ): ${ }^{(1)}$ Feeding ratio of monomers to initiator (BA for diblock copolymers or BDM for triblock copolymers);

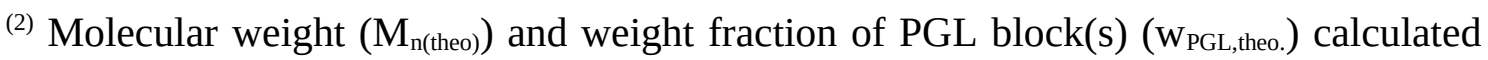
based on feeding ratio and monomer conversions (quantitative in all cases for both monomers); ${ }^{(3)}$ Degrees of polymerization of $\mathrm{BO}\left(\mathrm{DP}_{\mathrm{BO}}\right)$ and glycidol $\left(\mathrm{DP}_{\mathrm{GL}}\right)$, molecular weight ( $\left.\mathrm{M}_{\mathrm{n}(\mathrm{NMR})}\right)$ and weight fraction of PGL block(s) ( $\left.\mathrm{W}_{\mathrm{PGL}, \mathrm{NMR}}\right)$ calculated based on integral ratios in ${ }^{1} \mathrm{H}$ NMR spectrum; ${ }^{(4)}$ Number-average molecular weight $\left(\mathrm{M}_{\mathrm{n}(\mathrm{SEC})}\right)$ and 
polydispersity index (Đ) determined by SEC in DMF with PMMA as standard using RI detector.

Similarly, the characterization of the intermediates and products in triblock copolymerization, including $\mathrm{PBO}_{2 \mathrm{~m}}$ (homopolymerization mixture in fact), $\mathrm{PEEGE}_{\mathrm{n}}-b$ $\mathrm{PBO}_{2 \mathrm{~m}}-b-\mathrm{PEEGE}_{\mathrm{n}}$ and $\mathrm{PGL}_{\mathrm{n}}-b-\mathrm{PBO}_{2 \mathrm{~m}}-b-\mathrm{PGL}_{\mathrm{n}}$ by ${ }^{1} \mathrm{H}$ NMR (Figure S3, Supporting Informations) and GPC (Figure S4, Supporting Informations) evidences that the synthetic procedure by tBuP4-catalyzed sequential AROP and deprotection in acidic conditions can successfully be used in the synthesis of triblock copolymers. The characterization results of the triblock copolymers are compiled in Table 1 (from Row 3 to 7).

\section{Manufacturing and Characterization of the Block Copolymer Assemblies}

The manufacturing and characterization of block copolymer self-assemblies was further investigated. This has been performed by using the resources of static dynamic light scattering (SDLS), electrophoretic light scattering (ELS), transmission electron microcopy (TEM) and small angle x-ray scattering (SAXS). The autocorrelation functions acquired by DLS (representative examples are given in Figure 1a) were mathematically treated by using the NNLS analysis resulting in single populations of relaxation times (representative examples are given in Figure 2b) meaning, accordingly, single populations of scattering particles. 

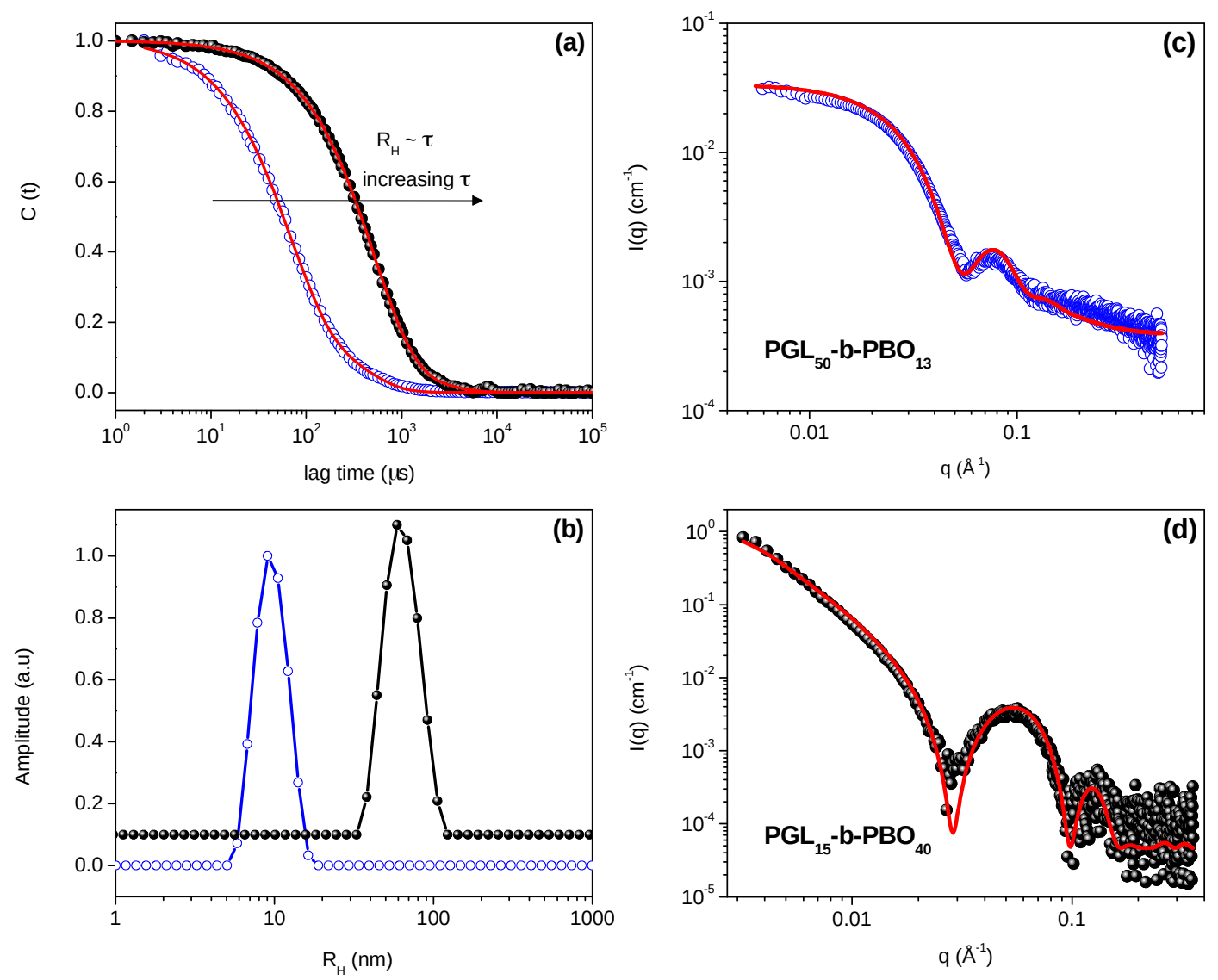

Figure 1. Scattering characterization of $\mathrm{PGL}_{50}-b-\mathrm{PBO}_{13}$ and $\mathrm{PGL}_{15}-b-\mathrm{PBO}_{40}$ selfassemblies according to the legend: (a) autocorrelation functions monitored at $90^{\circ}$; (b) respective distributions of $R_{\mathrm{H}}$, (c-d) respective SAXS patterns for $\mathrm{PGL}_{50}-b-\mathrm{PBO}_{13}$ and $\mathrm{PGL}_{15}-b-\mathrm{PBO}_{40}$ according to the legend.

Such behaviour was evidenced for the whole set of produced assemblies and the presence of monomodal distributions of relaxation times enabled the determination of hydrodynamic radius $\left(R_{\mathrm{H}}\right)$ and polydispersity $\left(\mu_{2} / \Gamma^{2}\right)$ via the Cumulant method. The static light scattering data (Debye plots) were also acquired and further one could 
determine $M_{w(N P s)}$ and $N_{\text {agg }}\left(M_{w(N P s)} / M_{w(\text { polymer })}\right)$. The values of $\zeta$-potential were taken from ELS measurements. The whole set of structural parameters determined (or further calculated) are summarized in Table 2 and subsequently discussed.

Table 2. Scattering data for manufactured micelles and polymersomes as determined by scattering techniques.

\begin{tabular}{|c|c|c|c|c|c|}
\hline Copolymer & $R_{\mathbf{H}}(\mathbf{n m})$ & PDI & $M_{w(\mathrm{NPs})} 10^{7}$ g. $\mathrm{mol}^{-1}$ & $N_{\text {agg }}$ & $\xi \mathrm{mV}$ \\
\hline \multicolumn{6}{|c|}{ Polymersomes } \\
\hline $\mathrm{PGL}_{20}-\boldsymbol{b}-\mathrm{PBO}_{84}-\boldsymbol{b}-\mathrm{PGL}_{20}$ & 79.6 & 0.40 & 3.76 & 3723 & -21.2 \\
\hline $\mathrm{PGL}_{10^{-}} b-\mathrm{PBO}_{88^{-}}-b-\mathrm{PGL}_{10}$ & 85.9 & 0.28 & 15.10 & 19400 & -10.3 \\
\hline $\mathrm{PGL}_{15}-\boldsymbol{b}-\mathrm{PBO}_{40}$ & 67.2 & 0.26 & 4.89 & 12300 & -24.3 \\
\hline \multicolumn{6}{|c|}{ Vesicles, Cylindrical and Star-Like Micelles } \\
\hline $\mathrm{PGL}_{15}-\boldsymbol{b}-\mathrm{PBO}_{44}-\boldsymbol{b}-\mathrm{PGL}_{15}$ & 81.5 & 0.18 & 3.07 & 4040 & -22.0 \\
\hline \multicolumn{6}{|c|}{ Star-Like Micelles } \\
\hline $\mathrm{PGL}_{11}-\boldsymbol{b}-\mathrm{PBO}_{22}-\boldsymbol{b}-\mathrm{PGL}_{11}$ & 24.0 & 0.19 & 0.46 & 933 & -19.0 \\
\hline $\mathrm{PGL}_{22}-\boldsymbol{b}-\mathrm{PBO}_{13}-\boldsymbol{b}-\mathrm{PGL}_{22}$ & 13.4 & 0.31 & 0.0668 & 155 & -22.4 \\
\hline $\mathrm{PGL}_{50}-b-\mathrm{PBO}_{13}$ & 9.7 & 0.34 & 0.0362 & 77 & -8.4 \\
\hline
\end{tabular}

The values of $R_{\mathrm{H}}$ are larger for polymersomes compared to star-like micelles. This reflects the higher values of $N_{\text {agg }}$ of the hollow structures, but mainly the presence of different morphologies depending on the hydrophobic-to-hydrophilic weight ratios as confirmed by transmission electron microscopy and small angle X-ray scattering measurements. The whole set of TEM images are portrayed in Figure 2. 

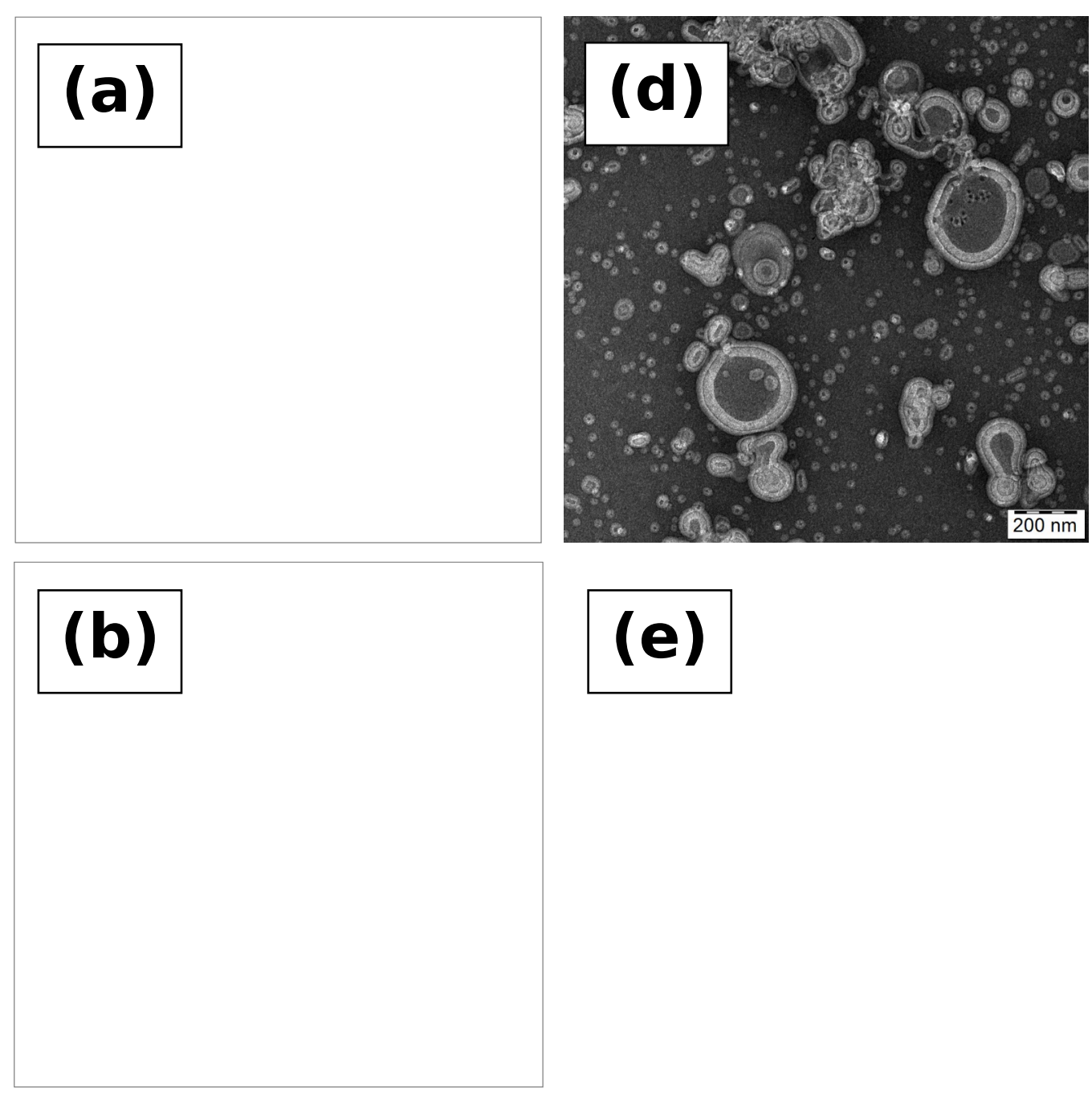

\section{(e)}
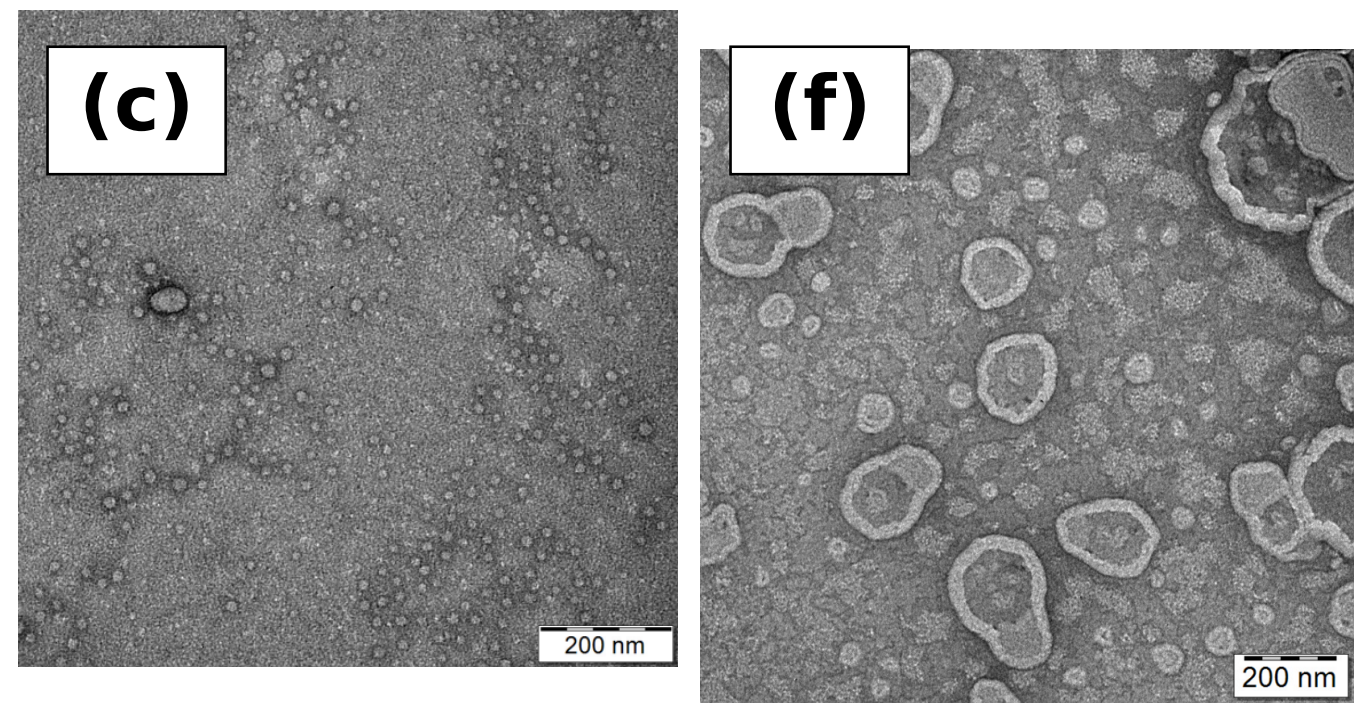

Figure 2. TEM images for $\mathrm{PGL}_{11}-b-\mathrm{PBO}_{22}-b-\mathrm{PGL}_{11}$ (a), $\mathrm{PGL}_{50}-b-\mathrm{PBO}_{13}$ (b), $\mathrm{PGL}_{22}-b-\mathrm{PBO}_{13}{ }^{-}$ $b$ - $\mathrm{PGL}_{22}$ (c), $\mathrm{PGL}_{10}-b-\mathrm{PBO}_{88}-b-\mathrm{PGL}_{10}$ (d), $\mathrm{PGL}_{15}-b-\mathrm{PBO}_{40}$ (e) and $\mathrm{PGL}_{20}-b-\mathrm{PBO}_{84}-b-\mathrm{PGL}_{20}$ (f). 
The image reported in Figure 2 (a-c) highlights predominantly the presence of small micellar structures ( 20-40 nm) in agreement with the size distributions obtained by dynamic light scattering as well as with the well-defined SAXS pattern given in Figure $1 \mathrm{~d}$ (representatively for $\mathrm{PGL}_{50}-b-\mathrm{PBO}_{13}$ ). The profile could be fitted by using the straightforward core-shell spherical form factor with $R_{\text {total }}=6 \mathrm{~nm}$. The micelles produced from $\mathrm{PGL}_{11}-b-\mathrm{PBO}_{22}-b$ - $\mathrm{PGL}_{11}$ are slightly larger reflecting the higher weight ratio of the hydrophobic PBO in the polymer chains thereby resulting in higher number of aggregation (Table 2). On the other hand, the images reported in Figure 2 (d-f) taken from $\mathrm{PGL}_{15}-b-\mathrm{PBO}_{40}, \mathrm{PGL}_{10}-b-\mathrm{PBO}_{88}-b-\mathrm{PGL}_{10}$ and $\mathrm{PGL}_{20}-b-\mathrm{PBO}_{84}-b-\mathrm{PGL}_{20}$ assemblies clearly confirm mainly the presence of vesicular structures with sizes no longer compatible to micellar objects. This has been also confirmed by SAXS measurements (as portrayed representatively for $\mathrm{PGL}_{15}-b-\mathrm{PBO}_{40}$ in Figure 2d). The profile is typical of vesicular structures and it was fitted by using the bilayer vesicle form factor with the thickness of the hydrophilic PGL shell in contact with water ( $\left.t_{\mathrm{h}}=3 \mathrm{~nm}\right)$ and the thickness of hydrophobic PBO layer $\left(t_{\mathrm{t}}=6.6 \mathrm{~nm}\right)$ as adjustable parameters. These results are in full agreement with the well-known phase diagram for the self-assembly of amphiphilic block copolymers in solution since polymersomes are expected at high weight ratios of the hydrophobic (PBO) segment. The TEM image taken from $\mathrm{PGL}_{15}-b$ $\mathrm{PBO}_{44}-b-\mathrm{PGL}_{15}$ (Figure S5 - Supporting Information File) on the other hand, is inconclusive to some extent regarding the main morphology. Although we cannot identify the mixture of morphologies by using light scattering measurements, there could be identified spherical particles (probably polymeric vesicles) along to cylindrical structures by microscopy. ${ }^{34}$

The values of $\zeta$-potential are highly negative regardless the morphology. Such feature, nevertheless, provided electrostatic stability to the assemblies as they are stable 
for months when stored at $4{ }^{\circ} \mathrm{C}$. Although we might expect that nanoparticles made from neutral organic polymer would not have surface charge $(\zeta \sim 0 \mathrm{mV})$ all the selfassembled structures had a negative zeta potential. This observation suggests that anions from the aqueous phase preferentially accumulate at the mobile Stern layer. The negative $\zeta$-potentials appear to arise from the preferential accumulation of $\mathrm{OH}^{-}$ions at the interface between water and the organic shell. This indeed seems to be a more general phenomenon. We have particularly measured negative $\zeta$-potentials for many different non-ionic particles. ${ }^{35-37}$

\section{Behavior in Protein Environments}

In order to evaluate the behavior of the polymeric assemblies in protein environments, we previously estimated the molar concentration of each protein required to cover the produced micelles and polymersomes. The details and computations are given in the Supporting Information File. We did not proceed with such investigations for $\mathrm{PGL}_{15}-b-\mathrm{PBO}_{44}-b-\mathrm{PGL}_{15}$ because of the existence of mixed morphologies (most probably vesicles and cylinders) thereby making unreliable such protocol for determining the required protein concentrations. The values of $N_{\text {Protein }}$ reported in Table S1 are the molar ratios [protein]/[NPs] required for fully covering each soft spherical nanoparticle. Based on these numbers, we monitored $R_{\mathrm{H}}$ as a function of protein concentration at least two times higher than $N_{\text {Protein }}$ $\left(2 N_{\text {Protein }}\right)$.

Indeed, the blood environment consists of over 3000 different proteins that are capable of interacting with nanomaterials producing the so-called protein-corona. Nevertheless, there are major proteins that were already identified on an assortment of polymeric nanoparticles of different size, chemical make-up and surface properties. 
Therefore, BSA, IgG and lysozyme were chosen as model proteins due to the pronounced differences in size, molecular weight and isoelectric point as given in Table S2.

The Figure 4 (left) portrays representatively the autocorrelation functions and

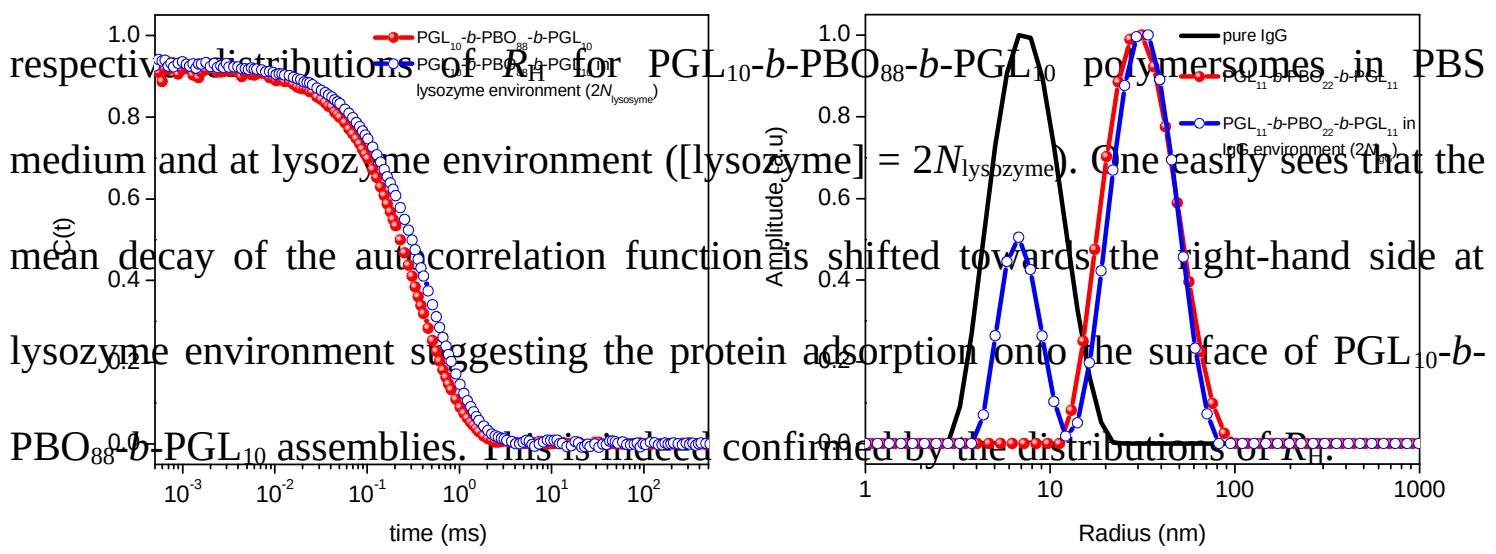
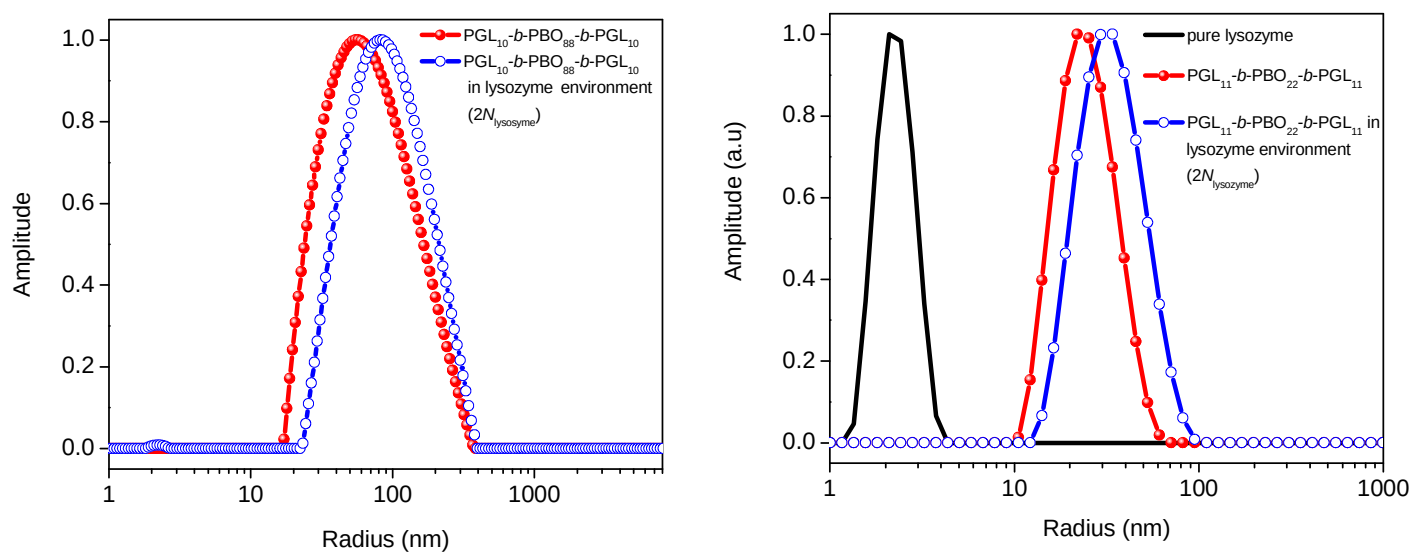

Figure 4. Dynamic light scattering data: (left) autocorrelation functions (top) and distributions of $R_{\mathrm{H}}$ (bottom) for $\mathrm{PGL}_{10}-b-\mathrm{PBO}_{88}-b-\mathrm{PGL}_{10}$ polymersomes in protein-free and at lysozyme environment ( $2 N_{\text {lysozyme }}$ ). (right) distributions of $R_{\mathrm{H}}$ for $\mathrm{PGL}_{11}-b-\mathrm{PBO}_{22}-$ 
$b$-PGL 11 micelles in PBS medium (full circles) and at IgG (top) and lysozyme (bottom) environments (open circles) at $2 N_{\text {protein. }}$.

The Figure 4 also portrays (right) the distributions of $R_{\mathrm{H}}$ for $\mathrm{PGL}_{11}-b-\mathrm{PBO}_{22}-b$ PGL $_{11}$ at IgG (top) and lysozyme (bottom) environments at $2 N_{\text {Protein. }}$ The data provided for IgG evidence that the size of the micellar assemblies remain essentially the same at the presence of the protein. The addition of IgG also induces the appearance of the light scattering contribution for free IgG (located at the left-hand side of the size distributions) thereby suggesting that the protein is not being adsorbed onto the surface of the polymeric assemblies. On the other hand, the data portrayed for lysozyme environment is remarkably different where one can notice the shift of the main particle population towards the right-hand side at the presence of the protein. This is a clear indication that protein adsorption is taking place. This methodological approach has been used to probe the adsorption of the model proteins at the surface of all produced self-assembled nanostructures and the quantitative results are all gathered in Table 3. This table reports the size $\left(R_{\mathrm{H}}\right)$ variation for vesicles and micelles before and after the contact with the different model protein environments. The values of $\Delta R_{\mathrm{H}}$ refer to $R_{\text {Hprotein-environment }}-R_{\text {Hprotein-free }}$ and they were monitored in the presence of protein concentration two times higher than the estimated amount to cover the whole polymer assemblies $\left(2 N_{\text {Protein }}\right)$. We understand that a robust indication of protein adsorption is evidenced when the monitored size of the assemblies increases at least the dimension $\left(D_{\mathrm{H}}=2 R_{\mathrm{H}}\right)$ of the model protein. The hydrodynamic diameters of the proteins are given in Table S2 (Supporting Information File). 
Table 3: Variation of the size of the nanostructures $\left(\Delta R_{\mathrm{H}}=R_{\text {Hprotein-environrment }}-R_{\text {Hprotein-free }}\right)$ considering the dimensions before and after the contact of the assemblies with the model proteins at $2 N_{\text {protein }}$.

\begin{tabular}{|c|c|c|c|}
\hline Entry & BSA & Lysozyme & IgG \\
\hline Polymersomes & & $\overline{\Delta R_{\mathrm{H}}(\mathrm{nm})}$ & \\
\hline $\mathrm{PGL}_{10}-b-\mathrm{PBO}_{88}-b-\mathrm{PGL}_{10}$ & $2 \pm 1$ & $8 \pm 1$ & $16 \pm 1$ \\
\hline $\mathrm{PGL}_{20}-b-\mathrm{PBO}_{84}-b-\mathrm{PGL}_{20}$ & $3 \pm 2$ & $2 \pm 1$ & $6 \pm 2$ \\
\hline $\mathrm{PGL}_{15}-\boldsymbol{b}-\mathrm{PBO}_{40}$ & $2 \pm 2$ & $12 \pm 3$ & $-2 \pm 1$ \\
\hline Star-Like Micelles & & & \\
\hline $\mathrm{PGL}_{11}-b-\mathrm{PBO}_{22}-b-\mathrm{PGL}_{11}$ & $-2 \pm 3$ & $9 \pm 2$ & $2 \pm 2$ \\
\hline $\mathrm{PGL}_{22}-\boldsymbol{b}-\mathrm{PBO}_{13}-\boldsymbol{b}-\mathrm{PGL}_{22}$ & $-1 \pm 2$ & $0 \pm 1$ & $3 \pm 2$ \\
\hline $\mathrm{PGL}_{50}-b-\mathrm{PBO}_{13}$ & $0 \pm 1$ & $2 \pm 1$ & $1 \pm 1$ \\
\hline
\end{tabular}

The Table 3 evidences that adsorption is protein-dependent with indications that electrostatic forces influence the phenomenon. Regardless the self-assembled structure, no evidences of BSA adsorption was observed. This is attributed to the highly negatively surfaces of the assemblies $(\sim-20 \mathrm{mV})$ and the isoelectric point of the BSA (pI 4.9) which confers to the biomacromolecules residual negative charges at $\mathrm{pH} 7.4$ thereby enabling protein-nanoparticle electrostatic repulsions. Similarly, the IgG adsorption is avoided expect for the assembly with the shortest PGL stabilizing shell ( $\mathrm{PGL}_{10}-b-\mathrm{PBO}_{88}-b-\mathrm{PGL}_{10}$ ). Taking into account the isoelectric point of IgG (pI 7.0), electrostatic repulsions may also contribute to the protein-repelling characteristic of the assemblies at least to some extent. Nevertheless, the particularly short PGL length in the $\mathrm{PGL}_{10}-b-\mathrm{PBO}_{88}-b-\mathrm{PGL}_{10}$ assemblies is not enough to provide full protein repulsion. The lysozyme adsorption is observed in block copolymer assemblies made by PGL blocks smaller than $\mathrm{DP}_{\mathrm{PGL}} \sim 20$. In such a case, size of the assemblies increases at the protein environment thus confirming protein adsorption. The lysozyme $\left(D_{\mathrm{H}}=4.2 \mathrm{~nm} ; \mathrm{pI}=10.5\right)$ adsorption indeed suggest the role of electrostatic forces in the phenomena. The high isoelectric point of lysozyme confers to the protein residual positive charges at $\mathrm{pH} 7.4$ 
then presumably enabling electrostatic attraction to the polymeric assemblies (that are negatively charged).

The thermodynamics of protein adsorption was further investigated by using the resources of isothermal titration calorimetry in order to provide a clearer scenario regarding the main forces driven the protein adsorption events. The Figure 5 portrays raw ITC data (left) and the values of energy per weight of injected protein as a function of protein-to-nanoparticle ratio (right) for the pairs where protein adsorption has been evidenced according to Table 3. Indeed, the raw ITC data already confirm protein adsorption since the process is accompanied by energy transfer. The resulting data set was fitted using the straightforward one set of binding site model. The molar enthalpy $(\Delta \mathrm{H})$, stoichiometry of binding $(N)$ that is, the number of protein molecules per nanoparticle and the equilibrium association constant $K_{\mathrm{A}}$ for the adsorption of lysozyme and IgG onto the block copolymer nanoparticles was obtained whenever possible by fitting the experimental data with the following equation:

$$
Q=\frac{N M_{t} \Delta H V_{\text {cell }}}{2}\left(1+\frac{1}{N K_{A} M_{t}}+\frac{X_{t}}{N M_{t}}-\sqrt{\left(1+\frac{1}{N K_{A} M_{t}}\right)^{2}-\frac{4 X_{t}}{N M_{t}}}\right)
$$

wherein $Q$ is heat content after each injection, $V_{\text {cell }}$ is the cell volume and $M_{\mathrm{t}}$ and $X_{\mathrm{t}}$ are respectively the molar concentration of nanoparticles and protein ( $V_{\text {cell, }}, M_{\mathrm{t}}, X_{\mathrm{t}}$ are known parameters, $Q$ is a measurable parameter and $N, K_{\mathrm{A}}$ and $\Delta \mathrm{H}$ are fitting parameters). Furthermore, the molar free energy change $(\Delta G)$ and the molar entropy change $(\Delta S)$ of the binding events were determined by using the following fundamental thermodynamic equations:

$$
\begin{gathered}
\Delta G=-R T \ln K_{A} \\
\Delta S=\frac{\Delta H-\Delta G}{T}
\end{gathered}
$$


The thermodynamic parameters obtained from the fitting approaches are provided in Table 4.
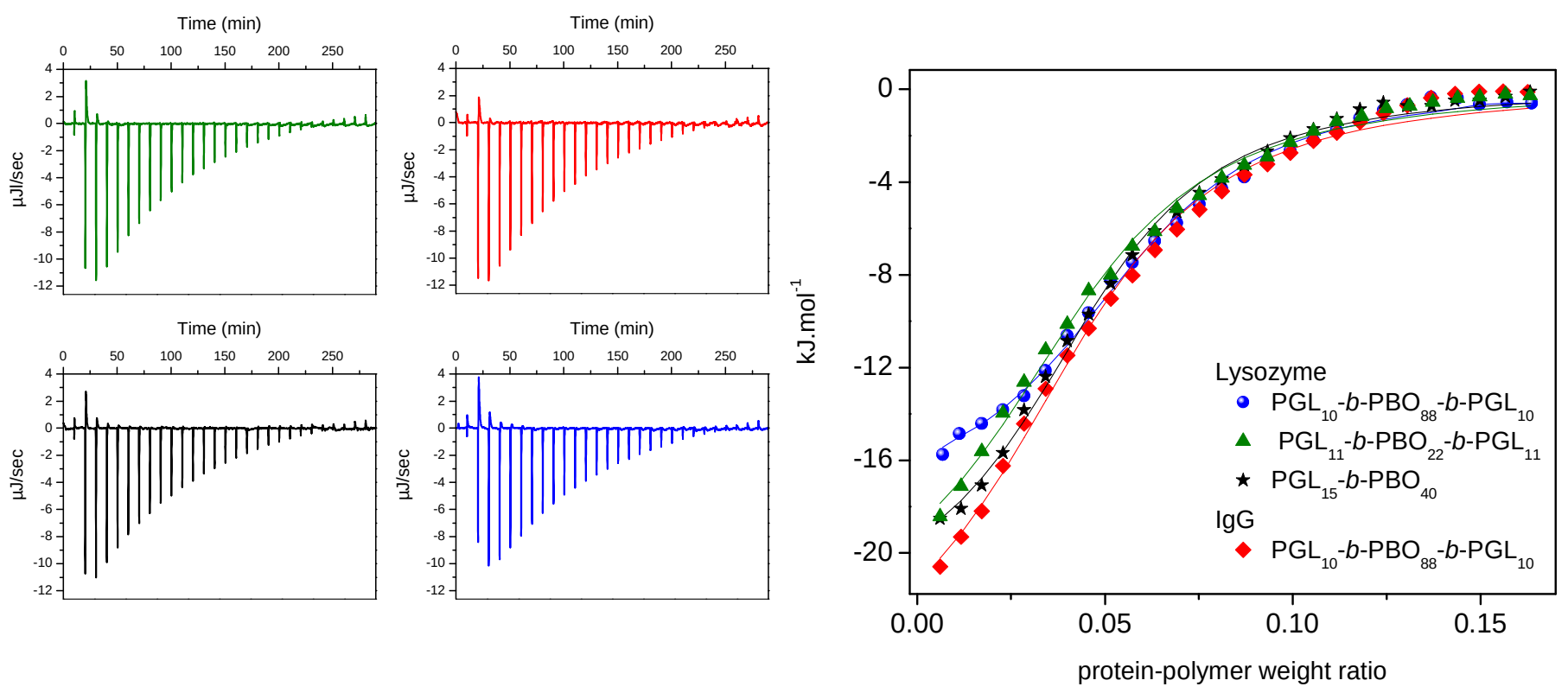

Figure 5. (left) ITC raw data for the titration of lysozyme and IgG into $\mathrm{PGL}_{\mathrm{m}}-b-\mathrm{PBO}_{\mathrm{n}}$ and $\mathrm{PGL}_{\mathrm{m}}-b-\mathrm{PBO}_{\mathrm{n}}-b-\mathrm{PGL}_{\mathrm{m}}$ block copolymer self-assemblies. (right) energy per weight of injected protein as a function of protein-to-nanoparticle weight ratio for the titration of self-assembled nanostructures according to the legend.

Table 4. Thermodynamic parameters obtained from ITC data

\begin{tabular}{|c|c|c|c|c|c|}
\hline Entry & $\begin{array}{c}\Delta \mathrm{H} \\
\left(\mathrm{kJ} \cdot \mathrm{mol}^{-1}\right)\end{array}$ & $\begin{array}{c}\mathrm{K} \\
\left(10^{4} \mathrm{M}^{-1}\right)\end{array}$ & $\begin{array}{l}\mathrm{N} \text { (protein/ } \\
\mathrm{NP})\end{array}$ & $\begin{array}{c}\Delta \mathrm{S} \\
\left(\mathrm{J} \cdot \mathrm{mol}^{-1} \mathrm{~K}^{-1}\right)\end{array}$ & $\begin{array}{c}\Delta \mathrm{G} \\
\left(\mathrm{kJ} \cdot \mathrm{mol}^{-1}\right)\end{array}$ \\
\hline
\end{tabular}




\begin{tabular}{|c|c|c|c|c|c|}
\hline $\begin{array}{c}\mathrm{PG}_{10}-b-\mathrm{PBO}_{88}-b-\mathrm{PG}_{10} \\
\text { Lysozyme }\end{array}$ & -18.0 & 5.89 & 0.0570 & 30.9 & -27.2 \\
\hline $\begin{array}{c}\mathrm{PG} 10-b-\mathrm{PBO}_{88}-b-\mathrm{PG}_{10} \\
\text { IgG }\end{array}$ & -26.4 & 4.10 & 0.0457 & -0.3 & -26.3 \\
\hline $\begin{array}{c}\mathrm{PG}_{15}-b-\mathrm{PBO}_{40} \\
\text { Lysozyme }\end{array}$ & -23.6 & 3.99 & 0.0445 & 8.9 & -26.2 \\
\hline $\begin{array}{c}\mathrm{PG}_{11}-b-\mathrm{PBO}_{22}-b-\mathrm{PG}_{11} \\
\text { Lysozyme }\end{array}$ & -22.7 & 5.41 & 0.0471 & 14.5 & -27.0 \\
\hline
\end{tabular}

The nanoparticle-protein binding is an exothermic process which certainly regards to the non-covalent bonding of proteins into the surface of the produced selfassemblies. The intermolecular forces may include electrostatic, hydrophobic, hydrogen bonding and van der Waals interactions. Accordingly, the values and signals of thermodynamic parameters are useful to make conclusions on the dominating intermolecular force responsible for the protein fouling. The hydrophobic interactions are dominant in endothermic and entropically-driven processes $(\Delta \mathrm{H}>0$ and $\Delta \mathrm{S}>0)$ whereas exothermic signals and positive entropy changes $(\Delta H<0$ and $\Delta S>0)$ are observed for the case of dominating electrostatic forces. The van der Waals and hydrogen bonding are usually the main operating forces when $\Delta \mathrm{H}<0$ and $\Delta \mathrm{S}<0$. Thus, the exothermic processes observed in the profiles suggest that the main force driven protein adsorption are note related to hydrophobic effects and they are then related to van der Waals, hydrogen bonding and-or electrostatic forces.

Indeed, the determined value of $\Delta S$ suggests the electrostatic interactions dominate the phenomenon of lysozyme adsorption. On the other hand, the IgG adsorption result in very small (although negative) value of $\Delta \mathrm{S}$ accordingly suggesting van der Waals and hydrogen bonding as the main operating intermolecular interactions. The surfaces charge of the assemblies is negative, and this supports the importance of 
electrostatic interaction regarding lysozyme adsorption. The nearly neutral surface charge of IgG at pH 7.4 (pI 7.0) is probably the responsible, on the other hand, by the presence of van der Waals and hydrogen bonding as the main driven forces in such pair.

The binding affinity $\left(K_{\mathrm{a}}\right)$ is different and the values evidence that lysozyme binds stronger to the nanoparticles as compared to IgG. The data reported in Table 4 also highlight stronger lysozyme binding on the surface of the $\mathrm{PGL}_{10}-b-\mathrm{PBO}_{88}-b-\mathrm{PGL}_{10}$ since the $K_{a}$ value is higher. Additionally, the lysozyme binding seems to be influenced by the PGL chain length since the binding affinity is weaker for assemblies with longer PGL-stabilizing shells.

Complementary, the ITC measurements were also used to confirm the nonexistence of protein adsorption events. In the supporting information file we provide ITC raw data for the titration of assemblies stabilized by short PGL stabilizing shells $\left(\mathrm{PGL}_{10}-b-\mathrm{PBO}_{88}-b-\mathrm{PGL}_{10}, \mathrm{PGL}_{11}-b-\mathrm{PBO}_{22}-b-\mathrm{PGL}_{11}\right.$ and $\mathrm{PGL}_{15}-b-\mathrm{PBO}_{40}$ ) in the presence of different proteins (Figure S6). The results highlight negligible energy transfer and the overall set of data robustly confirm that the protein adsorption is polymer lengthdependent and that the smaller length of the PGL stabilizing shells ( $\mathrm{DP}_{\mathrm{PGL}} \sim 20$ ) is already sufficient to provide protein-repelling characteristic to the assemblies, regardless the morphology.

Additionally, fluorescence spectroscopy data were acquired to evaluate possible protein conformational changes induced by the adsorption phenomena. The fluorescence spectroscopy is useful for probing the binding ability since the protein adsorption quenches the intrinsic fluorescence of different residues present in protein molecules such as tryptophan, tyrosine and phenylalanine. ${ }^{38}$ The Figure 6 (a) portrays the fluorescence spectra of lysozyme as a function of successive additions of $\mathrm{PGL}_{10}-b$ $\mathrm{PBO}_{88}-b-\mathrm{PGL}_{10}$. Similarly, the data for IgG as a function of successive additions of 
$\mathrm{PGL}_{15}-b-\mathrm{PBO}_{40}$ is given in Figure 6 (b). In these representative pairs, in agreement with the previous light scattering and ITC data, the quenching process is clear only for the pair lysozyme-PGL $\mathrm{L}_{10}-b-\mathrm{PBO}_{88}-b-\mathrm{PGL}_{10}$ since the fluorescence emission of the protein is progressively quenched as a function of nanoparticle concentration. The fluorescence spectrum, on the other hand, remains the same when IgG is titrated with $\mathrm{PGL}_{15}-b-\mathrm{PBO}_{40}$ . Indeed, the same profiles were monitored for the pairs where protein adsorption has not been suggested by DLS (this is not shown here for brevity). The fluorescence spectroscopy data were used to determine the Stern-Volmer quenching constant $\left(K_{\text {sv }}\right)$ for the nanoparticle-protein pairs where fluorescence quenching was evidenced.

$$
\frac{F_{0}}{F}=1+K_{\mathrm{sv}}[\mathrm{NPs}]
$$

being $F_{0}$ and $F$ the values of fluorescence intensity in the absence and presence of nanoparticles. These results are portrayed in Figure 6 (c) and Table 5.
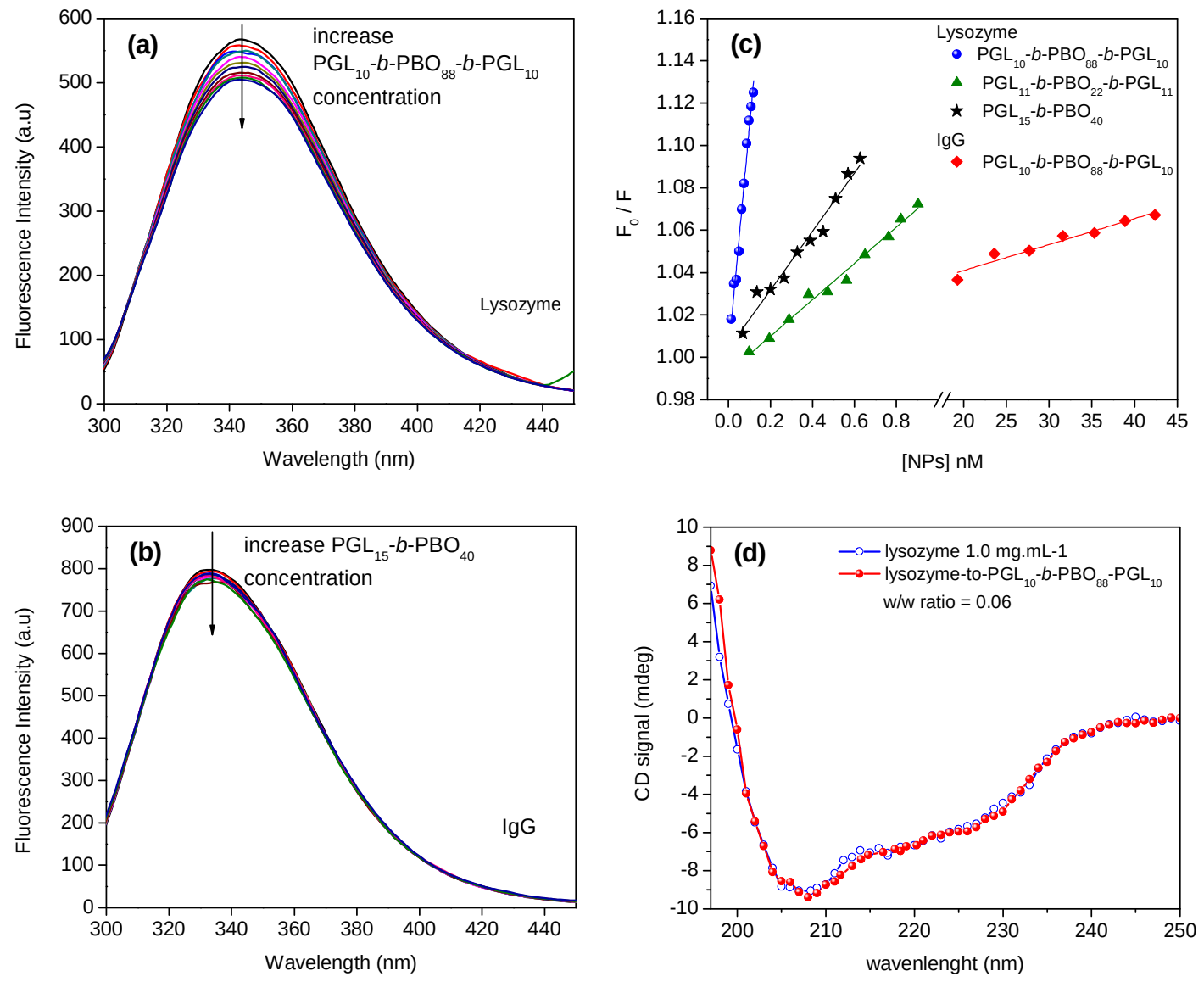
Figure 6. (left) Fluorescence spectra of lysozyme (a) as a function of successive additions of $\mathrm{PGL}_{10}-b-\mathrm{PBO}_{88}-b-\mathrm{PGL}_{10}$ and IgG (b) as a function of successive additions of $\mathrm{PGL}_{15}-b-\mathrm{PBO}_{40}$. (right) Stern-Volmer (c) plots for the fluorescence quenching of lysozyme and IgG by different block copolymer assemblies, and circular dichroism spectra of lysozyme at the presence of $\mathrm{PGL}_{10}-b-\mathrm{PBO}_{88}-b-\mathrm{PGL}_{10}$ assemblies at $\mathrm{w} / \mathrm{w}$ ratio $=0.06(\mathrm{~d})$.

Table 5. Stern-Volmer quenching constant determined for model proteins adsorbed onto the surface of different block copolymer assemblies as determined by fluorescence spectroscopy.

\begin{tabular}{|c|c|}
\hline Entry & $K_{\mathrm{SV}}$ \\
\hline & Lysozyme \\
\hline $\mathrm{PGL}_{10}-b-\mathrm{PBO}_{88}-b-\mathrm{PGL}_{10}$ & $1.07 \times 10^{9}$ \\
\hline $\mathrm{PGL}_{15}-\boldsymbol{b}-\mathrm{PBO}_{44}-\boldsymbol{b}-\mathrm{PGL}_{15}$ & $2.81 \times 10^{8}$ \\
\hline PGL $_{15}-b-\mathbf{P B O}_{40}$ & $1.38 \times 10^{8}$ \\
\hline \multirow{2}{*}{$\mathrm{PGL}_{11}-b-\mathrm{PBO}_{22}-b-\mathrm{PGL}_{11}$} & $8.58 \times 10^{7}$ \\
\hline & IgG \\
\hline PGL $_{10}-b-P_{B} O_{88}-b-P G L_{10}$ & $1.23 \times 10^{6}$ \\
\hline
\end{tabular}


The Stern-Volmer plot shows a good linear relationship as portrayed in Figure 6 (c). The data suggest the prevalence of one quenching mechanism (either static or dynamic quenching). The static quenching refers to the actual formation of groundstate complexes whereas the dynamic quenching is related to collisional encounters. The values of $K_{\mathrm{SV}}$ are in the range $\sim 10^{7}-10^{9} \mathrm{M}^{-1}$. The values of the quenching rate constant ( $\left.K_{\mathrm{b}}\right)$ were calculated as $K_{\mathrm{b}}=K_{\mathrm{sv}} / \tau_{0}$ considering $\tau_{0} \sim 10^{-8} \mathrm{~s}^{-1}$ as an average value for fluorescence? lifetime of proteins in the absence of quenchers. Accordingly, the values of $K_{\mathrm{b}}$ are remarkably greater than the value for threshold diffusion collision rate constant of quenchers to proteins $\left(2 \times 10^{10} \mathrm{M}^{-1} \mathrm{~s}^{-1}\right)$ thereby reflecting the involvement of static quenching by proper protein-nanoparticle interactions and ruling out collision effects since the linear profile suggest one dominating quenching mechanism. The absence of collision effects is indeed not surprising if one takes into account the low molar concentration of the nanoparticles. Overall, the fluorescence spectroscopy data agrees well with the DLS and ITC data confirming protein adsorption only at the surface of assemblies stabilized by short PGL.

Complementary, circular dichroism spectroscopy data were acquired to probe conformational changes in the structure of the proteins induced by the adsorption phenomenon. The CD spectra are portrayed representatively in Figure 6 (d) for pure lysozyme and at the presence of $\mathrm{PGL}_{10}-b-\mathrm{PBO}_{88}-b-\mathrm{PGL}_{10}$ polymeric assemblies. The lysozyme CD profile is characteristic of biomacromolecules with certain degree of $\alpha$ - 
helix content as evidenced by the minima at $208 \mathrm{~nm}$ and $207 \mathrm{~nm}$. One notices that the shapes and peak positions remained the same at the presence of the polymersomes highlighting that even when the adsorption takes place, it does cause major alterations in the conformation of the model proteins. This has also been evidence for other nanoparticle-protein pairs where the adsorption was confirmed by DLS, ITC and fluorescence spectroscopy.

\section{CONCLUSIONS}

We investigated the protein-repelling features of star-like micelles and polymersomes produced from $\mathrm{PGL}_{\mathrm{m}}-b-\mathrm{PBOn}_{\mathrm{n}}$ and $\mathrm{PGL}_{\mathrm{m}}-b-\mathrm{PBO}_{\mathrm{n}}-b-\mathrm{PGL}_{\mathrm{m}}$ block copolymers. The reported data evidences that protein adsorption is mainly influenced by the thickness of the stabilizing shells, regardless the morphology. The phenomenon is also influenced by the structural features of the proteins (essentially the isoelectric point). Whenever protein adsorption takes place, the phenomenon is exothermic and driven by electrostatic interaction (lysozyme) or hydrogen bonding and-or van der Walls interaction (IgG). The fluorescence spectroscopy measurements evidence that the binding is stronger on the surface of nanoparticles stabilized by shorter hydrophilic shells, although the phenomenon does not affect the secondary structure of the model proteins. Nevertheless, the most important finding of the current investigation is that the PGL hydrophilic polymer was evidenced to provide protein-repelling characteristic to polymeric assemblies even by using relatively short shells $\left(\mathrm{DP}_{\mathrm{PGL}} \sim 20\right)$ which is considerably shorter than the required of the well-known PEO - $\mathrm{DP}_{\mathrm{PEO}}(\sim 100$ units).

\section{ACKNOWLEDGMENTS}


These investigations were sponsored by FAPESP (Grant no. 2017/00459-4). F.C.G acknowledges the fellowship granted by FAPESP (Grant no. 2018/11038-2). H.D acknowledges the PhD scholarship offered by the China Scholarship Council (CSC).

\section{REFERENCES}

(1) Gaspar, R. Nanoparticles: Pushed off Target with Proteins. Nat. Nanotechnol. 2013, 8 (2), 79-80. https://doi.org/10.1038/nnano.2013.11.

(2) Müller, L. K.; Simon, J.; Rosenauer, C.; Mailänder, V.; Morsbach, S.; Landfester, K. The Transferability from Animal Models to Humans: Challenges Regarding Aggregation and Protein Corona Formation of Nanoparticles. $\begin{array}{lllll}\text { Biomacromolecules } & \text { 2018, } & 19 & \text { (2), }\end{array}$ https://doi.org/10.1021/acs.biomac.7b01472.

(3) Ke, P. C.; Lin, S.; Parak, W. J.; Davis, T. P.; Caruso, F. A Decade of the Protein Corona. ACS Nano 2017, 11 (12), 11773-11776. https://doi.org/10.1021/acsnano.7b08008.

(4) Obst, K.; Yealland, G.; Balzus, B.; Miceli, E.; Dimde, M.; Weise, C.; Eravci, M.; Bodmeier, R.; Haag, R.; Calderón, M.; et al. Protein Corona Formation on Colloidal Polymeric Nanoparticles and Polymeric Nanogels: Impact on Cellular Uptake, Toxicity, Immunogenicity, and Drug Release Properties. Biomacromolecules 2017, $18 \quad$ (6), 1762-1771. https://doi.org/10.1021/acs.biomac.7b00158.

(5) Caracciolo, G.; Farokhzad, O. C.; Mahmoudi, M. Biological Identity of Nanoparticles In Vivo: Clinical Implications of the Protein Corona. Trends 
Biotechnol. 2016, xx, 1-8. https://doi.org/10.1016/j.tibtech.2016.08.011.

(6) Lynch, I.; Cedervall, T.; Lundqvist, M.; Cabaleiro-Lago, C.; Linse, S.; Dawson, K. A. The Nanoparticle-Protein Complex as a Biological Entity; a Complex Fluids and Surface Science Challenge for the 21st Century. Adv. Colloid Interface Sci. 2007, 134-135, 167-174. https://doi.org/10.1016/j.cis.2007.04.021.

(7) Lundqvist, M.; Augustsson, C.; Lilja, M.; Lundkvist, K.; Dahlbäck, B.; Linse, S.; Cedervall, T. The Nanoparticle Protein Corona Formed in Human Blood or Human Blood Fractions. PLoS One 2017, 12 (4), e0175871. https://doi.org/10.1371/journal.pone.0175871.

(8) Mahmoudi, M.; Bertrand, N.; Zope, H.; Farokhzad, O. C. Emerging Understanding of the Protein Corona at the Nano-Bio Interfaces. Nano Today 2016, 11 (6), 817-832. https://doi.org/10.1016/j.nantod.2016.10.005.

(9) Nel, A. E.; Mädler, L.; Velegol, D.; Xia, T.; Hoek, E. M. V; Somasundaran, P.; Klaessig, F.; Castranova, V.; Thompson, M. Understanding Biophysicochemical Interactions at the Nano-Bio Interface. Nat. Mater. 2009, 8 (7), 543-557. https:// doi.org/10.1038/nmat2442.

(10) Wang, C.; Dong, L. Exploring 'New' Bioactivities of Polymers at the Nano-Bio Interface. Trends Biotechnol. 2015, $33 \quad$ (1), 10-14. https://doi.org/10.1016/j.tibtech.2014.11.002.

(11) Monopoli, M. P.; Åberg, C.; Salvati, A.; Dawson, K. a. Biomolecular Coronas Provide the Biological Identity of Nanosized Materials. Nat. Nanotechnol. 2012, 7 (12), 779-786. https://doi.org/10.1038/nnano.2012.207.

(12) Pearson, R. M.; Juettner, V. V.; Hong, S. Biomolecular Corona on Nanoparticles: A Survey of Recent Literature and Its Implications in Targeted Drug Delivery. Front. $\quad$ Chem. $\quad$ 2014, 2 (November), $\quad$ 1-7. 
https://doi.org/10.3389/fchem.2014.00108.

(13) Docter, D.; Westmeier, D.; Markiewicz, M.; Stolte, S.; Knauer, S. K.; Stauber, R.

H. The Nanoparticle Biomolecule Corona: Lessons Learned - Challenge

Accepted? Chem. Soc. Rev. 2015, 44 (17), 6094-6121. https://doi.org/10.1039/C5CS00217F.

(14) Caracciolo, G. Liposome-Protein Corona in a Physiological Environment: Challenges and Opportunities for Targeted Delivery of Nanomedicines. Nanomedicine Nanotechnology, Biol. Med. 2015, 11 (3), 543-557. https://doi.org/10.1016/j.nano.2014.11.003.

(15) Hamad, I.; Hunter, A. C.; Szebeni, J.; Moghimi, S. M. Poly(Ethylene Glycol)s Generate Complement Activation Products in Human Serum through Increased Alternative Pathway Turnover and a MASP-2-Dependent Process. Mol. Immunol. 2008, 46 (2), 225-232. https://doi.org/10.1016/j.molimm.2008.08.276.

(16) Zhang, P.; Sun, F.; Liu, S.; Jiang, S. Anti-PEG Antibodies in the Clinic: Current Issues and beyond PEGylation. J. Control. Release 2016, 244, 184-193. https://doi.org/10.1016/j.jconrel.2016.06.040.

(17) Kierstead, P. H.; Okochi, H.; Venditto, V. J.; Chuong, T. C.; Kivimae, S.; Fréchet, J. M. J.; Szoka, F. C. The Effect of Polymer Backbone Chemistry on the Induction of the Accelerated Blood Clearance in Polymer Modified Liposomes. J. Control. Release 2015, 213, 1-9. https://doi.org/10.1016/j.jconrel.2015.06.023.

(18) Schöttler, S.; Becker, G.; Winzen, S.; Steinbach, T.; Mohr, K.; Landfester, K.; Mailänder, V.; Wurm, F. R. Protein Adsorption Is Required for Stealth Effect of Poly(Ethylene Glycol)- and Poly(Phosphoester)-Coated Nanocarriers. Nat. Nanotechnol. 2016, 11 (4), 372-377. https://doi.org/10.1038/nnano.2015.330.

(19) Faye, I.; Huin, C.; Illy, N.; Bennevault, V.; Guégan, P. $\beta$-Cyclodextrin-Based 
Star Amphiphilic Copolymers: Synthesis, Characterization, and Evaluation as Artificial Channels. Macromol. Chem. Phys. 2019, 220 (2). https://doi.org/10.1002/macp.201800308.

(20) Gervais, M.; Brocas, A.; Cendejas, G.; Deffieux, A.; Carlotti, S. Synthesis of Linear High Molar Mass Glycidol-Based Polymers by Monomer-Activated Anionic Polymerization. Macromolecules 2010, 43 (4), 1778-1784. https://doi.org/10.1021/ma902286a.

(21) Misaka, H.; Tamura, E.; Makiguchi, K.; Kamoshida, K.; Sakai, R.; Satoh, T.; Kakuchi, T. Synthesis of End-Functionalized Polyethers by Phosphazene BaseCatalyzed Ring-Opening Polymerization of 1,2-Butylene Oxide and Glycidyl Ether. J. Polym. Sci. Part A Polym. Chem. 2012, 50 (10), 1941-1952. https://doi.org/10.1002/pola.25969.

(22) Backes, M.; Messager, L.; Mourran, A.; Keul, H.; Moeller, M. Synthesis and Thermal Properties of Well-Defined Amphiphilic Block Copolymers Based on Polyglycidol. Macromolecules 2010, 43 (7), 3238-3248. https://doi.org/10.1021/ ma902854r.

(23) Dentzer, L.; Bray, C.; Noinville, S.; Illy, N.; Guégan, P. Phosphazene-Promoted Metal-Free Ring-Opening Polymerization of 1,2-Epoxybutane Initiated by Secondary Amides. Macromolecules 2015, 48 (21), 7755-7764. https://doi.org/10.1021/acs.macromol.5b01638.

(24) Isono, T.; Kamoshida, K.; Satoh, Y.; Takaoka, T.; Sato, S.; Satoh, T.; Kakuchi, T. Synthesis of Star- and Figure-Eight-Shaped Polyethers by $\mathrm{t}-\mathrm{Bu}-\mathrm{P} 4$ Catalyzed Ring-Opening Polymerization of Butylene Oxide. Macromolecules 2013, 46 (10), 3841-3849. https://doi.org/10.1021/ma4006654.

(25) Kwon, W.; Rho, Y.; Kamoshida, K.; Kwon, K. H.; Jeong, Y. C.; Kim, J.; Misaka, 
H.; Shin, T. J.; Kim, J.; Kim, K.-W.; et al. Well-Defined Functional Linear Aliphatic Diblock Copolyethers: A Versatile Linear Aliphatic Polyether Platform for Selective Functionalizations and Various Nanostructures. Adv. Funct. Mater. 2012, 22 (24), 5194-5208. https://doi.org/10.1002/adfm.201201101.

(26) Dimitrov, P.; Rangelov, S.; Dworak, A.; Tsvetanov, C. B. Synthesis and Associating Properties of Poly(Ethoxyethyl Glycidyl Ether)/Poly(Propylene Oxide) Triblock Copolymers. Macromolecules 2004, 37 (3), 1000-1008. https://doi.org/10.1021/ma0354039.

(27) Isono, T.; Satoh, Y.; Miyachi, K.; Chen, Y.; Sato, S.; Tajima, K.; Satoh, T.; Kakuchi, T. Synthesis of Linear, Cyclic, Figure-Eight-Shaped, and TadpoleShaped Amphiphilic Block Copolyethers via t -Bu-P 4 -Catalyzed Ring-Opening Polymerization of Hydrophilic and Hydrophobic Glycidyl Ethers. Macromolecules 2014, 47 (9), 2853-2863. https://doi.org/10.1021/ma500494e.

(28) Satoh, Y.; Miyachi, K.; Matsuno, H.; Isono, T.; Tajima, K.; Kakuchi, T.; Satoh, T. Synthesis of Well-Defined Amphiphilic Star-Block and Miktoarm Star Copolyethers via t -Bu-P 4 -Catalyzed Ring-Opening Polymerization of Glycidyl Ethers. $\quad$ Macromolecules 2016, $49 \quad$ (2), 499-509. https://doi.org/10.1021/acs.macromol.5b02459.

(29) Gosecki, M.; Gadzinowski, M.; Gosecka, M.; Basinska, T.; Slomkowski, S. Polyglycidol, Its Derivatives, and Polyglycidol-Containing CopolymersSynthesis and Medical Applications. Polymers (Basel). 2016, 8 (6), 227. https://doi.org/10.3390/polym8060227.

(30) Otulakowski, Ł.; Gadzinowski, M.; Slomkowski, S.; Basinska, T.; Forys, A.; Dworak, A.; Trzebicka, B. Micellisation of Polystyrene-b-Polyglycidol Copolymers in Water Solution. Eur. Polym. J. 2018, 99 (December 2017), 72- 
79. https://doi.org/10.1016/j.eurpolymj.2017.12.010.

(31) Dworak, A.; Utrata-Wesołek, A.; Oleszko, N.; Wałach, W.; Trzebicka, B.; Anioł, J.; Sieroń, A. L.; Klama-Baryła, A.; Kawecki, M. Poly(2-Substituted-2Oxazoline) Surfaces for Dermal Fibroblasts Adhesion and Detachment. J. Mater. Sci. Mater. Med. 2014, 25 (4), 1149-1163. https://doi.org/10.1007/s10856-0135135-7.

(32) Lockhart, J. N.; Spoonmore, T. J.; McCurdy, M. W.; Rogers, B. R.; Guelcher, S. A.; Harth, E. Poly(Glycidol) Coating on Ultrahigh Molecular Weight Polyethylene for Reduced Biofilm Growth. ACS Appl. Mater. Interfaces 2018, 10 (4), 4050-4056. https://doi.org/10.1021/acsami.7b15981.

(33) Štěpánek, P. Dynamic Light Scattering: The Method and Some Applications. In Oxford Science Publications; Brown, W., Ed.; Oxford, 1993.

(34) Le Meins, J. F.; Sandre, O.; Lecommandoux, S. Recent Trends in the Tuning of Polymersomes' Membrane Properties. Eur. Phys. J. E 2011, 34 (2). https://doi.org/10.1140/epje/i2011-11014-y.

(35) de Castro, C. E.; Mattei, B.; Riske, K. a; Jäger, E.; Jäger, A.; Stepánek, P.; Giacomelli, F. C. Understanding the Structural Parameters of Biocompatible Nanoparticles Dictating Protein Fouling. Langmuir 2014, 30 (32), 9770-9779. https://doi.org/10.1021/la502179f.

(36) de Castro, C. E.; Bonvent, J.-J.; da Silva, M. C. C.; Castro, F. L. F.; Giacomelli, F. C. Influence of Structural Features on the Cellular Uptake Behavior of NonTargeted Polyester-Based Nanocarriers. Macromol. Biosci. 2016, 1-10. https://doi.org/10.1002/mabi.201600138.

(37) Ribeiro, C. A. S.; de Castro, C. E.; Albuquerque, L. J. C.; Batista, C. C. S.; Giacomelli, F. C. Biodegradable Nanoparticles as Nanomedicines: Are Drug- 
Loading Content and Release Mechanism Dictated by Particle Density? Colloid Polym. Sci. 2017, 295 (8), 1271-1280. https://doi.org/10.1007/s00396-016-40073.

(38) Hao, C.; Xu, G.; Feng, Y.; Lu, L.; Sun, W.; Sun, R. Fluorescence Quenching Study on the Interaction of Ferroferric Oxide Nanoparticles with Bovine Serum Albumin. Spectrochim. Acta - Part A Mol. Biomol. Spectrosc. 2017, 184, 191197. https://doi.org/10.1016/j.saa.2017.05.004. 